\title{
A Critical Review and Assessment of Different Thermoviscoplastic Material Models for Simultaneous Hot/Cold Forging Analysis
}

\author{
Marvin Nahrmann ${ }^{1} \cdot$ Anton Matzenmiller ${ }^{1}$ \\ Received: 15 October 2019 / Accepted: 17 March 2020 / Published online: 26 May 2020 \\ (C) The Author(s) 2020
}

\begin{abstract}
The simultaneous hot/cold forging is an innovative production process, taking advantage of the high accuracy for cold forming and low forces for hot forming. However, the choice of a suitable material model for such a large temperature range is a difficult issue and insufficiently regarded. Hence, the aim of this contribution is a critical review and assessment of the prediction capability and accuracy of three already existing thermo-viscoplasticity models. Therefore, the simulation results of the Bammann, ChIES a and Johnson (BCJ) model, the Evolving Microstructural Model of Inelasticity (EMMI) and a recently proposed user defined constitutive model by BRÖCKER and MATZENMILLER, based on an enhanced concept of rheological elements, are compared to test data considering a large range from room temperature up to approximately $1400 \mathrm{~K}\left(1127^{\circ} \mathrm{C}\right)$. All three material models may represent the thermo-viscoplastic characteristics of metals, whereby each investigated material model comprises different approaches for the temperature dependency of the initial yield stress, nonlinear isotropic hardening, and strain rate sensitivity. All material parameters are identified with the test data of the low alloy steel $50 \mathrm{CrV} 4 / 51 \mathrm{CrV} 4$, the case hardening steel $16 \mathrm{MnCr} 5$, the low carbon steel $\mathrm{C} 15$ and the aluminium alloy AlMgSi1 by using the commercial optimisation software LS-OPT. The prediction capability and accuracy of each model is evaluated on the basis of the mean squared error by means of a comparsion of real and predicted stress-strain curves for the four different metals. Finally, an industrial oriented hot/cold forging process for the production of a gear shaft made of the low alloy steel $51 \mathrm{CrV} 4$ is simulated with LS-DYNA using the three material models and, subsequently, their performance is discussed. As achievement of this model assessment, suitable as well as inappropriate temperature dependent approaches are identified for this large temperature range providing new insights into suitable material models for the analysis of a simultaneous hot/cold forging process.
\end{abstract}

Keywords Model Assessment · Thermo-Viscoplasticity · Parameter Identification · Simultaneous Hot/Cold Forging · Thermo-Mechanical Coupled FE Analysis · Model Validation

\section{Introduction}

The simultaneous hot/cold forging of bulk metals is an innovative production technology, taking advantage of the highly temperature-dependent mechanical behaviour under deformation (see [21], [23]). Thereby, hot and cold forging

Marvin Nahrmann

post-strucure@uni-kassel.de

Anton Matzenmiller

amat@uni-kassel.de

1 Institute of Mechanics, Department of Mechanical Engineering, University of Kassel, Moenchebergstr 7, 34125, Kassel, Germany are combined in a single step to achieve a high geometric accuracy in cold forged areas and low forming forces in the presence of large plastic strains in the heated sections (see [21] and [23]). Moreover, an integrated heat treatment leads to locally tailored component properties.

In modern product development, computer based simulation is involved for shortening the development time and reducing the costs. In forging simulations, the final workpiece geometry and the required forming force are subject matters of the investigation. For the analysis of the production process based on the finite element method (FEM), a suitable material model has to be used.

In order to capture the mechanical response under deformation of metals for various temperatures and strain rates, a thermo-viscoplastic material model is required. Due to the conditions of simultaneous hot/cold forging, the large 
range from room temperature up to approximately $1400 \mathrm{~K}$ $\left(1127^{\circ} \mathrm{C}\right)$ has to be considered for the modelling. The BCJ model according to BAMmann, CHIESA and Johnson has been developed to represent the characteristics of metals under the influences of temperature and strain rate (see [1] and [2]). A further development from the BCJ model is the Evolving Microstructural Model of Inelasticity (EMMI) proposed by MARIN and coworkers at the Sandia National Laboratories, USA (see [14]). Both material models are available in the material library of the commercial finite element (FE) software LSDYNA with the keywords *MAT_BAMMAN (*MAT_51) and *MAT_EMMI (*MAT_151) (see [12]). Furthermore, a material model based on an enhanced concept of rheological elements has been developed by BRÖCKER and MATZENMiLLER at the University of Kassel (see [4], [6], [5], and [7]). This new material model is implemented as a user defined material model into LS-DYNA.

Each investigated material model describes temperaturedependent nonlinear isotropic and kinematic hardening, thermally activated recovery effects and strain rate sensitivity. In this contribution, the aforementioned thermo-viscoplastic material models are evaluated for the application of simultaneous hot/cold forging analyses. Therefore, the numerical results are compared to test data of the low alloy steel $50 \mathrm{CrV} 4 / 51 \mathrm{CrV} 4$, the case hardening steel $16 \mathrm{MnCr} 5$, the low carbon steel $\mathrm{C} 15$ as well as the aluminium alloy $\mathrm{AlMgSi}$. For the purpose of model validation, a FE analysis of the simultaneous hot/cold forging process of a shaft made of the low alloy steel $51 \mathrm{CrV} 4$ is conducted finally. All FE simulations in this work are carried out with LS-DYNA.

\section{Simultaneous hot/cold forging of a gear shaft}

The moderate formability of metals at room temperature allows no large degrees of forming within the cold forging process. However, a high geometric accuracy is achieved. The ductility of metals is increased for hot forging processes

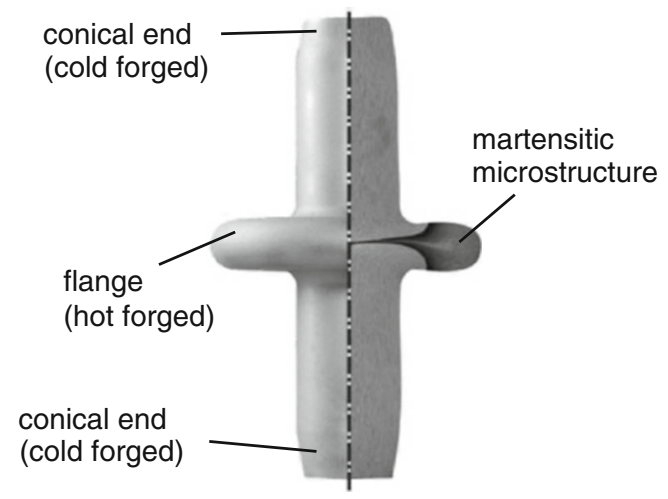

Fig. 1 Final workpiece of a gear shaft with locally tailored properties shaped by simultaneous hot/cold forging, [13]

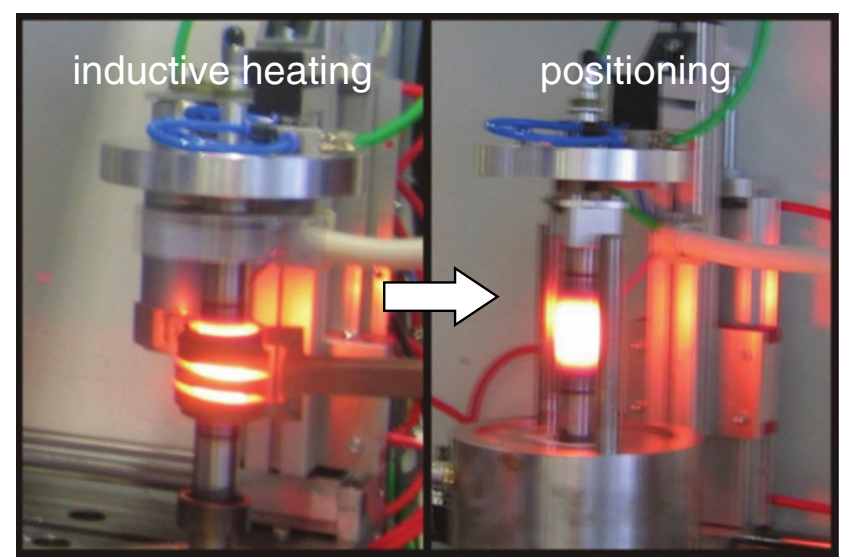

Fig. 2 Inductive heating in the middle of the shaft and positioning in lower forging die, [23]

leading to a significantly reduced forming force, but low geometric accuracy becomes a disadvantage. With the simultaneous hot/cold forging, a partial area of the component is heated and hot-forged, while other areas are cold-forged. Thus, the simultaneous hot/cold forging combines the advantages of cold and hot forging in a single production step.

As an exemplary production process, the simultaneous hot/cold forging of a gear shaft is summarised briefly. A more detailed description is presented in [21], [23], [8], [17], and [16]. The shaft is made of the low alloy steel $51 \mathrm{CrV} 4$, which is a heat treatable steel typically used for gear parts, pinions and shafts (see [18]). The conical ends of the shaft are shaped by cold forging and the flange is formed in the hot process (see Fig. 1, left). Moreover, an integrated heat treatment leads to a martensitic microstructure with high strength in the outer flange area (see Fig. 1, right). Compared to multi-step forging or machining, the production time and costs are reduced significantly.

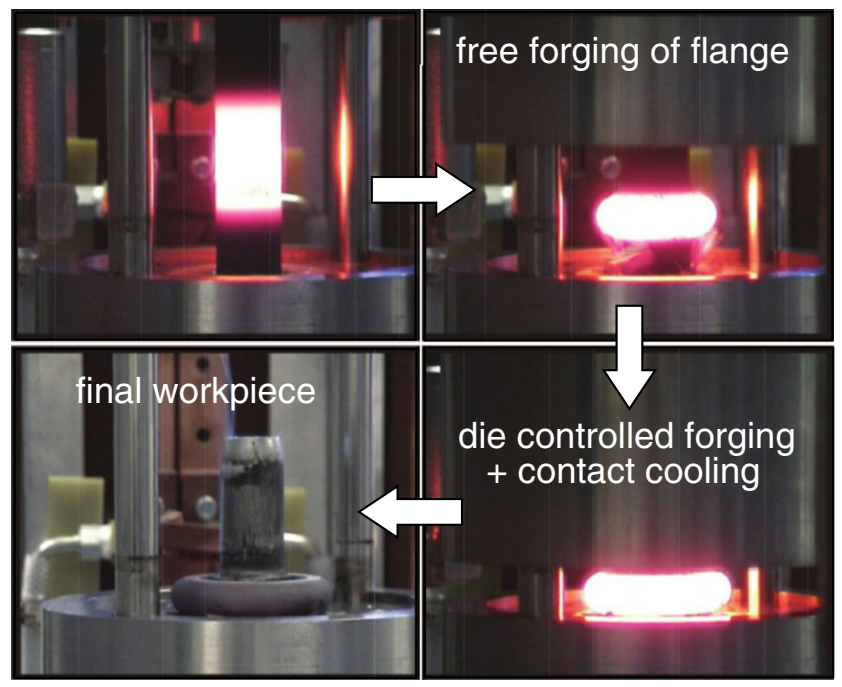

Fig. 3 Simultaneous hot/cold forging of the locally heated shaft and contact cooling, [23] 
The production process of the gear shaft consists of three steps. At first, the middle of the workpiece is inductively heated up to maximally $1623 \mathrm{~K}\left(1350{ }^{\circ} \mathrm{C}\right)$ for 12 seconds (see Fig. 2, left). Then, a heat conduction phase is applied for 5 seconds to achieve a homogeneous temperature distribution, whereby the induction power is strongly reduced. After local heating, the shaft is moved into the lower forging die and the simultaneous hot/cold forging starts after 23.8 seconds. Thereby, the temperature at the heated area of the shaft is maximally $1393 \mathrm{~K}\left(1120{ }^{\circ} \mathrm{C}\right)$. As a result of the highly temperature-dependent mechanical behaviour under deformation, the forming force is reduced significantly in the heated area. At first, the open die forging leads to bulging of the middle section of the shaft (see Fig. 3). Simultaneously, the cold forging shapes conical ends of the workpiece. Contact between the bulged material and the forging dies occurs after approximately 3.2 seconds. Thereby, the forming force is increased to maximally $1000 \mathrm{kN}$. The final flange geometry is formed eventually by the dies.

After simultaneous hot/cold forging, an integrated heat treatment similar to press hardening is applied. Thereby, the contact between the hot flange and the forging dies is maintained under high pressure of $1000 \mathrm{kN}$ for $28 \mathrm{~s}$. The complete process is finished after 55 seconds. The rapid cooling of the flange induces a martensitic microstructure in the outer flange area, where the gear teeth are located. As a result, the resistance of the gear teeth against wear is much higher.

\section{Evaluation method of material models}

For the FE analysis of simultaneous hot/cold forging processes, the choice of a suitable material model is crucial. This contribution aims to evaluate different material models for the FE analysis of such forging processes, where the process temperature ranges from $293 \mathrm{~K}\left(20{ }^{\circ} \mathrm{C}\right)$ up to approximately $1400 \mathrm{~K}\left(1127{ }^{\circ} \mathrm{C}\right)$ and has to be taken into account by the material model for the temperature dependency of the constitutive parameters.

The flow chart of the evaluation method of material models is shown as diagram in Fig. 4. As a very first step, the test data is considered closely to characterise the mechanical response under deformation. Afterwards, the material model is chosen to account for thermal, elastic, viscous and plastic effects. These effects can be modelled with rheological elements, connected in parallel or in series to a rheological network describing various aspects of the mechanical behaviour under deformation.

Each phenomenologically motivated material model contains unknown parameters that have to be calibrated to test data. Basically, the number of model parameters increases with the complexity of the material characteristics considered. Here, only selected subsets of the test data are used to reduce the effort of the identification part. The final step comprises the evaluation of material models, whereby FE simulations with optimised model parameters are compared to the complete set of test data. Thereby, the stress-strain curves, often denoted as yield curves in plasticity theory, from test data and simulation are evaluated based on the mean squared error (MSE).

\section{Test data and characterisation of the mechanical behaviour under deformation}

In general, the mechanical behaviour under deformation of metals is influenced by temperature and strain rate
Fig. 4 Diagram of the evaluation method of material models

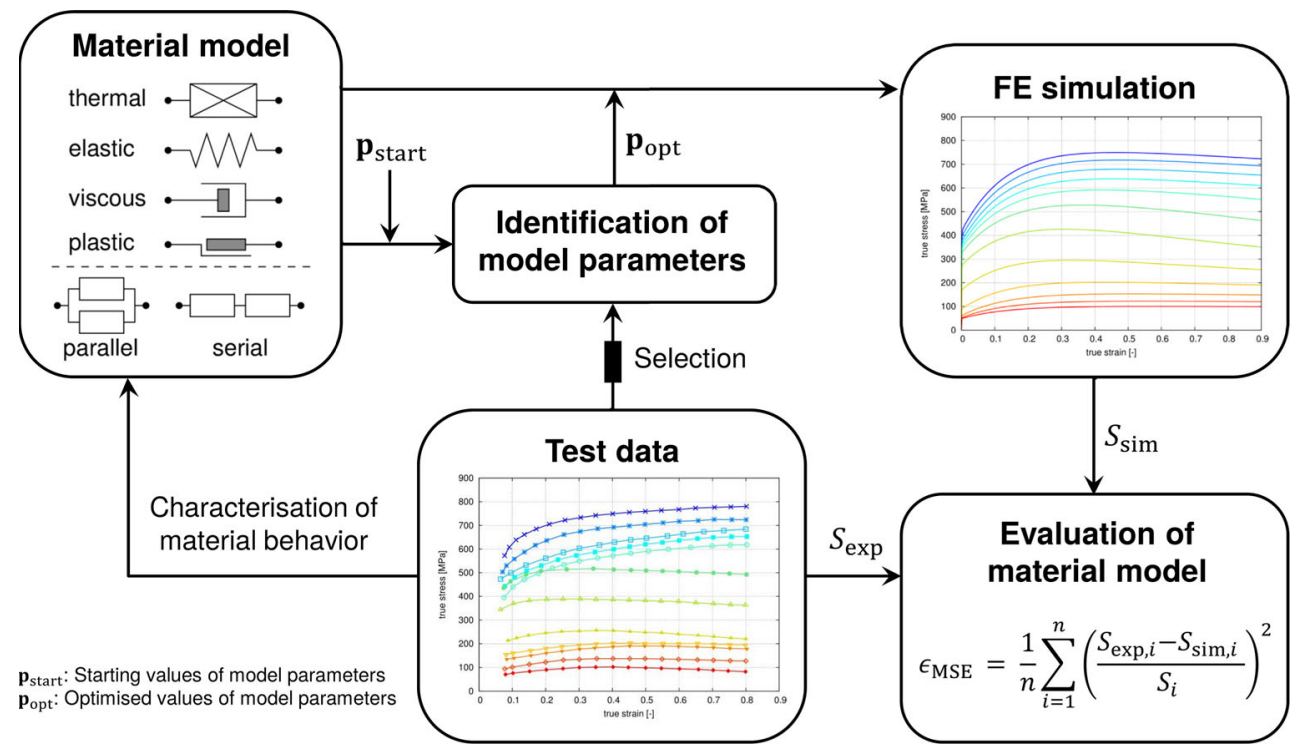



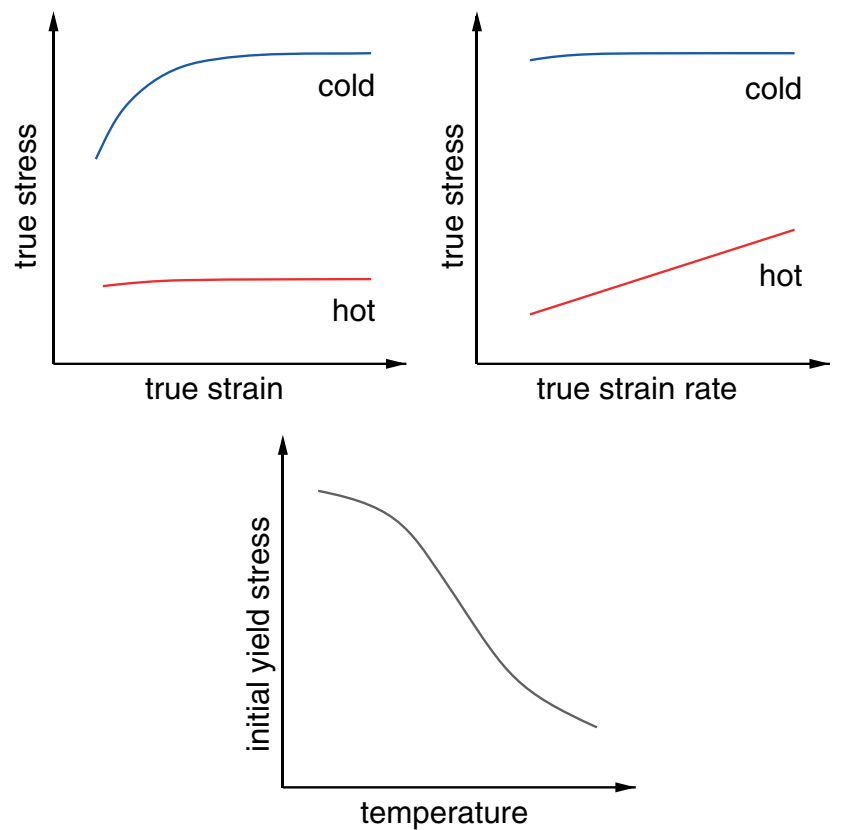

Fig. 5 Schematic diagram of temperature and strain rate dependent mechanical behaviour under deformation of metals (according to [10] p. 92)

(see Fig. 5) as well as the microstructure and stress/strain state. However, the focus of this contribution is on the temperature and strain rate influence, and therefore, the effect of the microstructure on the mechanical response is neglected. The initial yield stress depends strongly on the temperature, whereby it decreases with rising temperature. Metals show an extensive hardening behaviour at room temperature, whereas the hardening nearly vanishes at higher temperatures. The hardening saturation is caused by thermally activated recovery processes, and therefore, it is also named dynamic recovery. A further recovery process is the static recovery, whereby the hardening stress reduces during a holding time at high temperature. Moreover, there is a strain rate dependence as well, mainly noticeable at high temperature. Hence, the strain rate sensitivity is a function of temperature. A further temperature-dependent effect is thermal softening, where the yield stress decreases due to the temperature rise during forming caused by partly conversion of plastic work into heat. As a result, the FE analysis of simultaneous hot/cold forging processes requires a temperature and rate dependent plasticity model.

In this contribution, test data for stress-strain curves of four different metals is considered at a large temperature range and at different strain rates. The experimental data of the case hardening steel $16 \mathrm{MnCr} 5$ as well as the low carbon steel $\mathrm{C} 15$ are given in [10] in dependence the true strain rate at $1.61 / \mathrm{s}, 8.01 / \mathrm{s}$ and $40.01 / \mathrm{s}$. Thereby, the temperature range of $16 \mathrm{MnCr} 5$ is given from $293 \mathrm{~K}\left(20^{\circ} \mathrm{C}\right)$ up to $1373 \mathrm{~K}$ $\left(1100{ }^{\circ} \mathrm{C}\right)$, respectively from $293 \mathrm{~K}\left(20^{\circ} \mathrm{C}\right)$ up to $1473 \mathrm{~K}$ $\left(1200{ }^{\circ} \mathrm{C}\right)$ for $\mathrm{C} 15$. For both alloys, the experimental data is generated by upsetting uniaxial tests. In addition, the test data of the aluminium alloy $\mathrm{AlMgSi} 1$ is considered within a temperature range from $573 \mathrm{~K}\left(300{ }^{\circ} \mathrm{C}\right)$ up to $773 \mathrm{~K}$ $\left(500^{\circ} \mathrm{C}\right)$ at the true strain rate of $0.3 \mathrm{1} / \mathrm{s}, 3.0 \mathrm{1} / \mathrm{s}$ and $100 \mathrm{1} / \mathrm{s}$. The test data of AlMgSil is experimentally determined as before and taken from [10] as well. It should be mentioned that the temperature range is only given for hot forging here. The experimental data of the low alloy steel 50CrV4 is presented in [11] within a temperature range from $1073 \mathrm{~K}$ $\left(800{ }^{\circ} \mathrm{C}\right)$ to $1423 \mathrm{~K}\left(1150^{\circ} \mathrm{C}\right)$ and true strain rates between $0.001 \mathrm{1} / \mathrm{s}$ and $10.0 \mathrm{1} / \mathrm{s}$. The test data of the $50 \mathrm{CrV} 4$ alloy is experimentally determined by upsetting tests. Due to the absence of test data for the temperature range lower than $1073 \mathrm{~K}\left(800{ }^{\circ} \mathrm{C}\right)$ of $50 \mathrm{CrV} 4$, experimental substitute data are used of the nearly similar low steel alloy $51 \mathrm{CrV} 4$ for the temperature range between $273 \mathrm{~K}\left(20^{\circ} \mathrm{C}\right)$ and $973 \mathrm{~K}$ $\left(700{ }^{\circ} \mathrm{C}\right.$ ), at the engineering (eng.) strain rate of $0.025 \mathrm{1} / \mathrm{s}$ 1 . It is assumed that both materials $50 \mathrm{CrV} 4$ and $51 \mathrm{CrV} 4$ have nearly the same mechanical properties and, therefore, they are used equivalently for the evaluation of the various material models.

Usually in metal forging, the experimental data is generated by upsetting tests to achieve large degrees of forming. In contrast to the other alloys investigated, the experimental data of $51 \mathrm{CrV} 4$ is found by tensile tests. Thereby, plastic instability leads to necking of the specimen resulting in premature rupture. Hence, only small up to moderate deformations can be achieved with tensile tests. To achieve large forming degrees, stress-strain curves are derived from the tension test data in [16] and are applied in this contribution. All of the aforementioned test data are summarised in Table 1. For the FE simulations, it must be distinguished between tensile loading with constant engineering strain rate and compressive loading with constant true strain rate.

\section{Thermo-viscoplastic material models}

As a result of the characterisation of the mechanical behaviour under deformation in Section "Test data and characterisation of the mechanical behaviour under deformation", the material model have to take temperature and rate dependent plasticity into account. This kind of constitutive approach is also referred to as thermo-viscoplastic material modelling. In this contribution, two thermo-viscoplastic constitutive theories are considered as part of the material library of LSDYNA namely the BAMMANN-CHIESA-JOHNSON (BCJ)

\footnotetext{
${ }^{1}$ The test data of $51 \mathrm{CrV} 4$ in the temperature range from $273 \mathrm{~K}\left(20^{\circ} \mathrm{C}\right)$ to $973 \mathrm{~K}\left(700{ }^{\circ} \mathrm{C}\right)$ is kindly provided by Prof. Dr.-Ing. B. Scholtes, Institute of Material Science, Department of Mechanical Engineering, University of Kassel, Mönchebergstr. 3, 34125 Kassel (Germany)
} 
Table 1 Overview of the investigated test data of different metals

\begin{tabular}{|c|c|c|c|c|}
\hline Material & Type & Temperature & Strain rate & Testing method \\
\hline $16 \mathrm{MnCr} 5$ & $\begin{array}{l}\text { Case hardening } \\
\text { steel }\end{array}$ & $\begin{array}{l}293-1373 \mathrm{~K} \\
\left(20-1100^{\circ} \mathrm{C}\right)\end{array}$ & $\begin{array}{l}1.6,8.0,40.01 / \mathrm{s} \\
\text { (true strain rate) }\end{array}$ & Upsetting test \\
\hline C15 & Low carbon steel & $\begin{array}{l}293-1473 \mathrm{~K} \\
\left(20-1200^{\circ} \mathrm{C}\right)\end{array}$ & $\begin{array}{l}1.6,8.0,40.01 / \mathrm{s} \\
\text { (true strain rate) }\end{array}$ & Upsetting test \\
\hline $51 \mathrm{CrV} 4$ & Low alloy steel & $\begin{array}{l}293-973 \mathrm{~K} \\
\left(20-700{ }^{\circ} \mathrm{C}\right)\end{array}$ & $\begin{array}{l}0.0251 / \mathrm{s} \\
\text { (eng. strain rate) }\end{array}$ & Tensile test \\
\hline $50 \mathrm{CrV} 4$ & Low alloy steel & $\begin{array}{l}1073-1473 \mathrm{~K} \\
\left(800-1150^{\circ} \mathrm{C}\right)\end{array}$ & $\begin{array}{l}0.001,0.01,0.1,1,5,10.01 / \mathrm{s} \\
\text { (true strain rate) }\end{array}$ & Upsetting test \\
\hline AlMgSi1 & Aluminium alloy & $\begin{array}{l}573-773 \mathrm{~K} \\
\left(300-500^{\circ} \mathrm{C}\right)\end{array}$ & $\begin{array}{l}0.3,3.0,100.01 / \mathrm{s} \\
\text { (true strain rate) }\end{array}$ & Upsetting test \\
\hline
\end{tabular}

model as well as the Evolving Microstructural Model of Inelasticity (EMMI). Both models consider the conversion of dissipated work into heat $w_{\text {diss }}$ by means of the TAYLORQUINNEY approximation based on the plastic work $w_{\mathrm{pl}}-$ see [22].

$w_{\text {diss }}=\gamma_{\mathrm{TQ}} w_{\mathrm{pl}}$

This approach assumes, that the locally generated heat is proportionally to the amount of plastic work dissipated with $\gamma_{\text {TQ }}$ as the TAYLOR-QUINNEY coefficient. The coefficient is stated to be in the range of 0.85-0.95 in [19], 0.9-0.95 in [1] and 0.8-1.0 in [14]. However, experimental results in [3] and [9] show, that the stored energy depends on the plastic work in a nonproportional manner in general. Therefore, the TAYLOR-QUINNEY assumption of proportional energy dissipation and storage is mostly used, if no test data of stored energy is available.

Moreover, a new thermo-viscoplasticity model, developed by BRÖCKER and MATZENMILLER at the University of Kassel, is investigated in this contribution. The new thermo-viscoplasticity model has been implemented into LS-DYNA as a user defined material model. The constitutive equations of the user material approach are based on an enhanced concept of rheological elements-see Fig. 6. Thereby, each rheological body is connected to a certain material characteristic, which allows a straightforward interpretation of the constitutive behaviour.

Furthermore, the rheological elements are associated to energy storage (white elements) or energy dissipation (grey elements). The free energy $\psi$ of the model is determined, containing the energy storage of the linear elastic spring $\left(\psi_{\mathrm{el}}\right)$, the thermal element $\left(\psi_{\mathrm{th}}\right)$, the friction element $\left(\psi_{\kappa_{0}}\right)$, the isotropic $\left(\psi_{\kappa}\right)$ and the kinematic hardening element $\left(\psi_{\xi}\right)$ by

$$
\begin{aligned}
\psi & =\psi_{\mathrm{el}}+\psi_{\mathrm{th}}+\psi_{\kappa_{0}}+\psi_{\kappa}+\psi_{\xi} \\
& =\frac{1}{\rho}\left[\frac{1}{2} E \varepsilon_{\mathrm{el}}^{2}-\frac{1}{2 \theta_{0}} \rho c_{v}\left(\theta-\theta_{0}\right)^{2}+\kappa_{0} \bar{h}_{\mathrm{e}}+\frac{1}{2} E_{\kappa}{\overline{r_{\mathrm{e}}}}^{2}+\frac{1}{2} E_{\xi} y_{\mathrm{e}}^{2}\right]
\end{aligned}
$$

see [5], Eq. (50) and (51). In order to calculate the mechanical dissipation $\delta_{\mathrm{M}}$, the viscoplastic stress power is reduced by the derivation of the free energy with respect to the according element strain multiplied by the according strain rate, leading to the inequality

$\delta_{\mathrm{M}}=\frac{1}{\rho} \sigma \dot{\varepsilon}_{\mathrm{vp}}-\frac{\partial \psi}{\partial \bar{h}_{\mathrm{e}}} \dot{\bar{h}}_{\mathrm{e}}-\frac{\partial \psi}{\partial \bar{r}_{\mathrm{e}}} \dot{\bar{r}}_{\mathrm{e}}-\frac{\partial \psi}{\partial y_{\mathrm{e}}} \dot{y}_{\mathrm{e}} \geq 0$,
Fig. 6 Rheological network of the user defined material model in uniaxial case of small strains, [4]

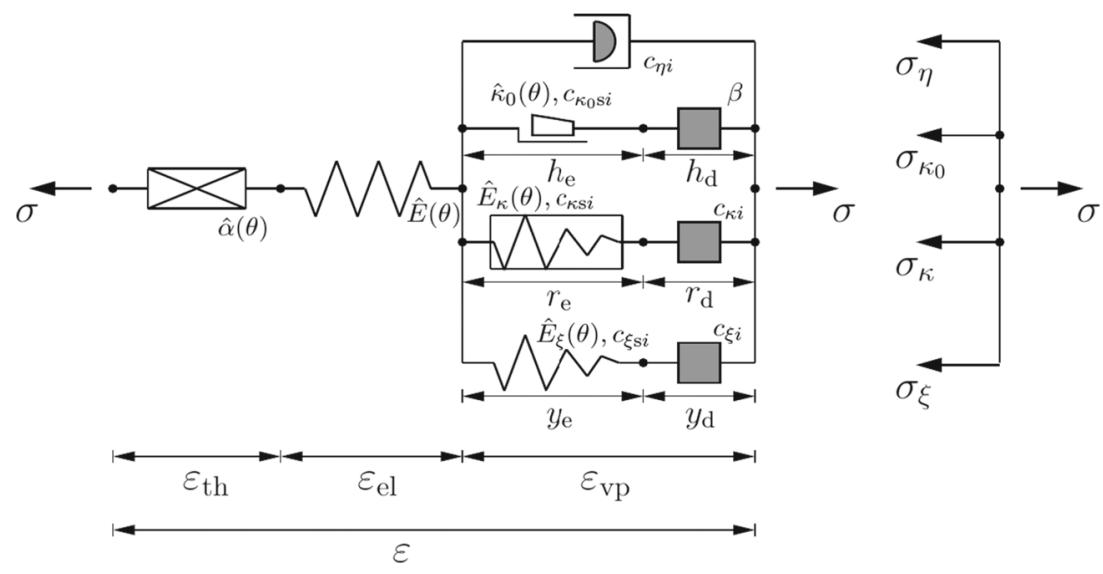


see [5], Eq. (52). Finally, the mechanical dissipation is applied as an additional volumetric heat source within the heat equation. This approach results in a better prediction of plastic work converted into heat, see [5] and [7].

For small elastic deformations, the rate of deformation tensor can be split into an elastic, a viscoplastic and a thermal part.

$\mathbf{D}=\mathbf{D}_{\mathrm{el}}+\mathbf{D}_{\mathrm{vp}}+\mathbf{D}_{\mathrm{th}}$

For isotropic materials, the thermal part of the rate of deformation tensor is given by

$\mathbf{D}_{\mathrm{th}}=\hat{\alpha}(\theta) \dot{\theta} \mathbf{1}$,

whereby $\hat{\alpha}(\theta)$ is the temperature-dependent thermal expansion coefficient. The absolute temperature in KELVIN degree is denoted as $\theta$. In general, the yield behaviour of metals is isotropic and pressure independent, and hence, the VON MISES yield function is mostly used. Thus, the yield criterion depends only on the second invariant of the stress deviator. The yield function $F$ with temperature-dependent initial yield stress $Y(\theta)$ and temperature-dependent isotropic hardening $\kappa(\theta)$ is proposed for all three investigated material models with

$F=\sqrt{\frac{3}{2}}\left\|\mathbf{T}^{\mathrm{D}}\right\|-(Y(\theta)+\kappa(\theta))$.

Thereby, the norm of the deviatoric stress tensor $\mathbf{T}^{\mathrm{D}}$ is chosen as

$\left\|\mathbf{T}^{\mathrm{D}}\right\|=\sqrt{\mathbf{T}^{\mathrm{D}} \cdot \mathbf{T}^{\mathrm{D}}}$.

If the yield condition $F>0$ is fulfilled, the elastic limit is reached and viscoplastic deformations occur, defined by the flow rule

$\mathbf{D}_{\mathrm{vp}}=\lambda \mathbf{N}\left(\mathbf{T}^{\mathrm{D}}\right)$,

whereby $\lambda$ is the viscoplastic multiplier and $\mathbf{N}\left(\mathbf{T}^{\mathrm{D}}\right)$ generates a tensor with the direction information of the stress deviator.

$\mathbf{N}\left(\mathbf{T}^{\mathrm{D}}\right)=\frac{\mathbf{T}^{\mathrm{D}}}{\left\|\mathbf{T}^{\mathrm{D}}\right\|}$

The constitutive equations of the EMMI material model are carried out in a dimensionless form. According to [14] p. 28 , the non-dimensional equations lead to a simpler fit of the material parameters and increase the numerical robustness. However, additional parameters are needed. The parameters to normalise the variables in the constitutive equations are the shear modulus $G$, the bulk modulus $K$, the melting temperature $\theta_{\mathrm{M}}$, the BURGER's vector $b$, and the lattice diffusion $D_{v}$-see [14]. The normalised variables are denoted by the breve symbol $(\breve{\bullet})$. All the necessary parameters for the normalisation are summarised in Table 5 .
The normalised time

$\breve{t}=\frac{t}{t_{\mathrm{c}}}$

is determined by means of the characteristic time.

$t_{\mathrm{c}}=\frac{b^{2}}{D_{v}}$

Thereby, the lattice diffusion $D_{\nu}$ is calculated from the term

$D_{v}=D_{0 v} \exp \left(\frac{-Q_{v}}{R \theta_{\mathrm{M}}}\right)$.

The normalised time derivative of a dimensionless quantity is given by

$(\stackrel{*}{\bullet})=\frac{\mathrm{d}(\breve{\bullet})}{\mathrm{d} \breve{t}}=t_{\mathrm{c}} \frac{\mathrm{d}(\breve{\bullet})}{\mathrm{d} t}$.

The homologous temperature $\breve{\theta}$ is defined by means of the melting point $\theta_{\mathrm{M}}$ :

$\breve{\theta}=\frac{\theta}{\theta_{\mathrm{M}}}$

The normalised time derivative of the homologous temperature is obtained from

$\stackrel{*}{\ddot{\theta}}=\frac{t_{\mathrm{c}}}{\theta_{\mathrm{M}}} \dot{\theta}$.

See [14] for more detailed information about the nondimensional formulation of the constitutive equations of the EMMI model.

Each of the three investigated thermo-viscoplastic material models considers different temperature dependencies for the YounG's modulus, initial yield stress, nonlinear isotropic and kinematic hardening, strain rate sensitivity, static recovery and damage evolution. Due to the absence of sufficient test data, the material models cannot be applied with their complete features here. Since no test data for temperature dependent elasticity is available, the YounG's modulus is modelled as temperature independent. Due to large plastic but only small elastic deformations, this assumption does not have a significant influence on the final results of the geometry and the forces. The kinematic hardening has an influence on the mechanical behaviour for compression followed by tensile loading and vice versa. However, no cyclic tests are available for the investigated steel and aluminium alloys. Therefore, the model assessment is limited to monotonic loading conditions only. As a consequence, hardening is completely described by the isotropic behaviour. Furthermore, the models approach to static recovery and damage evolution is not considered as well, because neither recovery effects nor the damage behaviour is part of the model evaluation. Therefore, only the temperature-dependent initial yield stress, the isotropic hardening as well as the strain-rate-sensitivity is considered for the assessment of the three material models in this contribution. 
Table 2 Approaches of the temperature dependent initial yield stress

\begin{tabular}{llr}
\hline Model & Approach & Parameters \\
\hline BCJ Model & $Y=C_{3} \exp \left(C_{4} / \theta\right)$ & $C_{3}, C_{4}$ \\
EMMI Model & $\breve{Y}=\frac{\breve{m}_{1}}{1+\breve{m}_{2} \exp \left(-\breve{m}_{3} / \breve{\theta}\right)} \frac{1}{2}\left[1+\tanh \left(\breve{m}_{4}\left(\breve{m}_{5}-\breve{\theta}\right)\right)\right]$ & $\breve{m}_{1}, \breve{m}_{2}, \breve{m}_{3}, \breve{m}_{4}, \breve{m}_{5}$ \\
Proposed Model & $Y=\kappa_{0} \frac{1}{2}\left(1+\tanh \left(Q_{\kappa_{0}}\left(\theta_{\kappa_{0}}-\theta\right)\right)\right)$ & $\kappa_{0}, Q_{\kappa_{0}}, \theta_{\kappa_{0}}$ \\
\hline
\end{tabular}

The temperature-dependent interpolation of the initial yield stress and their associated parameters are summarised in Table 2 for each of the three different material models. For the BCJ model, the initial yield stress $Y$ is described by an exponential function with two parameters. The EMMI model combines an inverse exponential function with a hyperbolic tangent function and, therefore, five parameters are needed in total. For the initial yield stress of the user defined material model, the hyperbolic tangent function tanh is applied with three parameters and consequently is a special case of the EMMI model for $\breve{m}_{2}=0$.

The temperature dependent isotropic hardening function with its associated parameters is summarised in Table 3 for each of the three different models. Here, the effective viscoplastic strain is denoted as $\bar{E}_{\mathrm{vp}}$. The isotropic hardening function contains a hardening and a saturation term. For the hardening assumption of the BCJ model, the exponential decay function $H$ and the inverse exponential saturation function $R_{\mathrm{d}}$ are applied, whereby a total of four parameters is necessary. The temperature-dependent isotropic hardening approach of the EMMI model includes the constant hardening modulus $\breve{H}$ and the temperaturedependent saturation function $\breve{R}_{\mathrm{D}}$ for which an inverse exponential function is taken analogously to the approach of the BCJ model with an overall of three parameters. For the proposed model, the hardening is described by the temperature-dependent hardening function $\hat{E}_{\kappa}$ and the constant saturation parameter $\varepsilon_{\kappa}^{\infty}$. The temperature dependence of the hardening term is described by a hyperbolic tangent function tanh with a total of four constitutive parameters.

The proposals for the temperature-dependent strain rate sensitivity and their associated parameters are summarised in Table 4 for all three different models, where the viscoplastic multiplier $\lambda$ is used to represent the strain rate sensitivity. Its temperature dependency is taken into account by a temperature dependent prefactor. For the BCJ and the EMMI model, the prefactor $f$ respectively $\breve{f}$ can be interpreted as the pseudo-fluidity. Its inverse in the proposed model is the prefactor $\eta$, which can be interpreted as pseudo-viscosity. In the case of the BCJ model, the yield function $F$ as well as a so-called drag-stress, denoted as $V$, are used as arguments of the hyperbolic sine function. The drag stress $V$ depends on the temperature, through an exponential function applied here. In the EMMI model an additional exponent $\breve{n}$ is placed over the hyperbolic sine function. Thereby, the exponent is a nonlinear function of the temperature. The drag-stress of the EMMI model is set up by applying the initial yield stress $Y$ and the isotropic hardening $\kappa$ as the denominator. Just like in the EMMI model, the proposed model introduces a temperature dependent exponent $\hat{m}$ representing an additional temperature dependency of the plastic multiplier, whereby a nonlinear function of temperature is used for it as well. For the drag-stress $\hat{D}$ of the proposed model, the user can decide whether a drag stress is generated similar to the EMMI model with the initial yield stress $Y$ and isotropic hardening $\kappa$, or to normalise the yield function $F$. The first

Table 3 Approaches of the temperature dependent isotropic hardening

\begin{tabular}{lll}
\hline Model & Approach & Parameters \\
\hline BCJ Model & $\dot{\kappa}=\left(H(\theta)-R_{\mathrm{d}}(\theta) \kappa^{2}\right) \dot{\bar{E}}_{\mathrm{vp}}$ & $C_{13}, C_{14}, C_{15}, C_{16}$ \\
& $H(\theta)=C_{15} \exp \left(C_{16} / \theta\right), \quad R_{\mathrm{d}}(\theta)=C_{13} \exp \left(-C_{14} / \theta\right)$ & $\breve{c}_{5}, \breve{c}_{6}, \breve{Q}_{3}$ \\
EMMI Model & $\stackrel{*}{\kappa}=\left(\breve{H}-\breve{R}_{\mathrm{D}}(\breve{\theta}) \breve{\kappa}\right) \bar{E}_{\mathrm{vp}}$ & $E_{\kappa}, Q_{\kappa}, \theta_{\kappa}, \varepsilon_{\kappa}^{\infty}$ \\
& $\breve{H}=\breve{c}_{6}, \quad \breve{R}_{\mathrm{D}}(\breve{\theta})=\breve{c}_{5} \exp \left(-\breve{Q}_{3} / \breve{\theta}\right)$ & \\
Proposed Model & $\dot{\kappa}=\left(\hat{E}_{\kappa}(\theta)-\frac{\kappa}{\left.\varepsilon_{\kappa}^{\infty}\right) \dot{\bar{E}}_{\mathrm{vp}}+\frac{\partial_{\theta} \hat{E}_{\kappa}(\theta)}{\hat{E}_{\kappa} \theta} \kappa \dot{\theta}}\right.$ \\
& $\hat{E}_{\kappa}(\theta)=\frac{1}{2} E_{\kappa}\left(1+\tanh \left(Q_{\kappa}\left(\theta_{\kappa}-\theta\right)\right)\right)$ &
\end{tabular}


Table 4 Approaches of the temperature dependent strain rate sensitivity

\begin{tabular}{|c|c|c|}
\hline Model & Approach & Parameters \\
\hline BCJ Model & $\begin{array}{l}\lambda=f(\theta) \sinh \left\langle\frac{F}{V(\theta)}\right\rangle \\
f(\theta)=C_{5} \exp \left(-C_{6} / \theta\right), \quad V(\theta)=C_{1} \exp \left(-C_{2} / \theta\right)\end{array}$ & $C_{1}, C_{2}, C_{5}, C_{6}$ \\
\hline EMMI Model & $\begin{array}{l}\lambda=\breve{f}(\breve{\theta})\left[\sinh \left\langle\frac{\breve{F}}{\breve{\kappa}+\breve{Y}(\breve{\theta})}\right\rangle\right]^{\check{n}(\theta)} \\
\breve{f}(\breve{\theta})=\breve{c}_{2} \exp \left(\frac{-\breve{Q}_{1}}{\breve{\theta}}\right), \quad \breve{n}(\breve{\theta})=\frac{\breve{c}_{9}}{\breve{\theta}}+\breve{c}_{1}\end{array}$ & $\breve{c}_{1}, \breve{c}_{2}, \breve{c}_{9}, \breve{Q}_{1}$ \\
\hline Proposed Model & $\begin{array}{ll}\lambda=\frac{1}{\hat{\eta}(\theta)}\left\langle\frac{F}{\hat{D}(\kappa, \theta)}\right\rangle^{\hat{m}(\theta)}, \quad \hat{D}(\kappa, \theta):=D_{0}+D_{1}(Y(\theta)+\kappa) \\
\hat{\eta}(\theta)=\eta \exp (Q \eta / \theta), \quad \hat{m}(\theta)=m_{0}+\frac{m_{1}}{\theta}\end{array}$ & $\eta, Q_{\eta}, m_{0}, m_{1}$ \\
\hline
\end{tabular}

option can be achieved in the proposed model by setting $D_{0}=0$ and $D_{1}=1$. In this contribution, the parameters $D_{0}=10^{6} \mathrm{~N} / \mathrm{m}$ and $D_{1}=0$ are chosen for the steel types $16 \mathrm{MnCr} 5, \mathrm{C} 15$, and the aluminium alloy AlMgSi1. Hence, the yield function $F$ is normalised and, thus, no drag-stress is active. For the low alloy steel 50/51CrV4, the dragstress is enabled with $D_{0}=0$ and $D_{1}=1$ leading to a better agreement with test data. Each of the three models investigated requires four parameters to account for the temperature dependent strain rate sensitivity.

The constitutive equations of the $\mathrm{BCJ}$ model require 10 parameters in total. For the EMMI model, 12 parameters are needed to calibrate the material model to the test data. Additionally, 5 parameters are required for the dimensionless formulation of the constitutive equations in the EMMI model. For the proposed model, an overall number of 11 parameters have to be identified.

\section{Identification of model parameters}

The unknown model parameters are identified by fitting the stress-strain response of the simulation to the stress-strain course of the test data for the various metal types (see Section "Test data and characterisation of the mechanical behaviour under deformation"). The inverse problem of parameter identification leads to a nonlinear optimisation problem, solved in this contribution by the commercial software LS-OPT (see [20]). For this, the mean squared error (MSE)

$\epsilon_{\mathrm{MSE}}=\frac{1}{n} \sum_{i=1}^{n}\left(\frac{S_{\mathrm{exp}, i}-S_{\mathrm{sim}, i}}{S_{i}}\right)^{2}$

is calculated during the optimisation process to evaluate the deviation between the test data and the simulation results for the chosen set of parameters. Here, $S_{\text {exp }}$ relates to the test data, $S_{\text {sim }}$ to the simulation result, and $S$ is a scaling factor, which is the maximum from the test data here. Moreover, $n$ is the total number of data pairs. In order to achieve an optimised model parameter set, the MSE is minimised within the optimisation procedure.

Only a selection of the test data is used for the optimisation procedure to reduce the effort of the identification process. Hence, the stress-strain curves at $293 \mathrm{~K}, 373 \mathrm{~K}$, $773 \mathrm{~K}, 1073 \mathrm{~K}$ and $1373 \mathrm{~K}$ are considered for the steel alloy $16 \mathrm{MnCr} 5$, whereas the stress-strain curves at $293 \mathrm{~K}$, $373 \mathrm{~K}, 773 \mathrm{~K}, 1173 \mathrm{~K}$ and $1473 \mathrm{~K}$ are applied for the alloy $\mathrm{C} 15$ as well as $573 \mathrm{~K}, 673 \mathrm{~K}$ and $773 \mathrm{~K}$ for AlMgSi1. For 50/51CrV4, the temperatures $293 \mathrm{~K}, 573 \mathrm{~K}, 773 \mathrm{~K}$ and $973 \mathrm{~K}$ are used for the identification at the strain rate of $0.0251 / \mathrm{s}$. Moreover, the stress-strain curve at the medium temperature $1073 \mathrm{~K}$ is considered for the rates of $0.1 \mathrm{1} / \mathrm{s}$ and $1.0 \mathrm{1} / \mathrm{s}$. At the temperature level of $1273 \mathrm{~K}$, the strain rates of $0.0011 / \mathrm{s}, 0.11 / \mathrm{s}, 11 / \mathrm{s}, 51 / \mathrm{s}$ and $101 / \mathrm{s}$ are taken into account. The highest temperature $1423 \mathrm{~K}$ is applied at the strain rate of $0.11 / \mathrm{s}$. These selected test data are compared to its counterparts from the FE simulation run with LS-DYNA. For simplicity, the FE simulations are carried out using a single eight-node solid element with initial edge lengths of $L_{0}=10 \mathrm{~mm}$. The displacement of all nodes of the upper element side are prescribed as the loading. The degrees of freedom of the lower nodes are restraint in order to generate a uniaxial stress state. As mentioned in Section "Test data and characterisation of the mechanical behaviour under deformation", there are two different loading conditions: tensile and compressive load. The engineering strain rate

$\dot{\varepsilon}_{\text {eng }}=\left(\frac{\Delta L(t)}{L_{0}}\right)=\frac{\dot{u}(t)}{L_{0}}$

is kept constant during the run for the applied tensile test, whereas the true strain rate

$\dot{\varepsilon}_{\text {true }}=\left(\ln \left(\frac{L(t)}{L_{0}}\right)\right)=\frac{\dot{u}(t)}{L(t)}$ 
Table 5 Parameters for the dimensionless form of the EMMI material model

\begin{tabular}{lllll}
\hline Parameter & Symbol & Unit & Steel & Aluminium \\
\hline BURGERS vector & $b$ & $\mathrm{~m}$ & $2.580 \cdot 10^{-10}$ & $2.860 \cdot 10^{-10}$ \\
Melting temperature & $\theta_{\mathrm{M}}$ & $\mathrm{K}$ & 1800.0 & 933.0 \\
Lattice diffusion (prefactor) & $D_{0 v}$ & $\mathrm{~m}^{2} / \mathrm{s}$ & $3.70 \cdot 10^{-5}$ & $1.70 \cdot 10^{-4}$ \\
Lattice diffusion (activation energy) & $Q_{v}$ & $\mathrm{~J} / \mathrm{mol}$ & $280.0 \cdot 10^{3}$ & $142.0 \cdot 10^{3}$ \\
Universal gas constant & $R$ & $\mathrm{~J} /(\mathrm{mol} \mathrm{K})$ & 8.314 & 8.314 \\
\hline
\end{tabular}

is unchanged during the simulation of the applied upsetting tests (see Table 1). Since, the change in length $\Delta L(t)$ is equal to the displacement $u(t)$, the displacement function

$u(t)=\dot{\varepsilon}_{\text {eng }} L_{0} t$

is linear in time for a constant engineering strain rate. Note the relation between engineering and true strain is:

$\varepsilon_{\text {true }}=\ln \left(1+\varepsilon_{\text {eng }}\right)$

Hence, the relation between the rate of engineering and true strain is obtained by:

$\dot{\varepsilon}_{\text {true }}=\frac{\dot{\varepsilon}_{\text {eng }}}{1+\varepsilon_{\text {eng }}}$

With Eq. 18, the true strain rate can be expressed as:

$\dot{\varepsilon}_{\text {true }}=\frac{\dot{u}(t)}{L_{0}+u(t)}$

The rearrangement leads to the differential equation:

$\dot{u}(t)-\dot{\varepsilon}_{\text {true }} u(t)=\dot{\varepsilon}_{\text {true }} L_{0}$

with the solution

$u(t)=C \exp \left(\dot{\varepsilon}_{\text {true }} t\right)-L_{0}$.

The constant $C$ is determined by assuming the inital displacement value as zero.

$u(0)=0 \quad \Rightarrow \quad C=L_{0}$
Finally, the nonlinear time dependent displacement function

$u(t)=L_{0}\left(\exp \left(\dot{\varepsilon}_{\text {true }} t\right)-1\right)$

is achieved with a constant true strain rate.

During forging processes, thermo-mechanical coupling occurs due to the mutual interactions of the displacement and the temperature field. To solve the thermo-mechanical coupled problem with LS-DYNA, the staggered solution scheme is used in the sense of a blockwise GAUSS-SEIDEL solution method, where the displacement equations are solved with fixed temperatures and the thermal problem is determined with fixed displacements. The thermal and mechanical time step size are chosen identically to achieve a high temporal resolution, whereby an implicit solver is applied in both cases.

Since no test data are available for the identification of the parameters in the temperature dependent YounG's modulus, the elastic parameters are kept constant here. For simplicity, it is assumed that all steel materials investigated have the same elastic properties with YounG's modulus as $210 \cdot 10^{9} \mathrm{~N} / \mathrm{m}^{2}$, POISSON ratio as 0.3 and the density as $7890 \mathrm{~kg} / \mathrm{m}^{3}$. For the aluminium alloy, the YounG's modulus is $70 \cdot 10^{9} \mathrm{~N} / \mathrm{m}^{2}$, POISSON ratio is 0.34 and the density is $2700 \mathrm{~kg} / \mathrm{m}^{3}$. For the TAYLOR-QUINNEY

Table 6 Identified parameters of the BCJ model

\begin{tabular}{|c|c|c|c|c|c|c|}
\hline & & & $16 \mathrm{MnCr} 5$ & $\mathrm{C} 15$ & $50 / 51 \mathrm{CrV} 4$ & AlMgSi1 \\
\hline \multirow[t]{2}{*}{ initial yield stress } & $C_{3}$ & {$\left[\mathrm{~N} / \mathrm{m}^{2}\right]$} & $1.7004 \cdot 10^{7}$ & $4.7033 \cdot 10^{6}$ & $1.0000 \cdot 10^{7}$ & $3.8078 \cdot 10^{4}$ \\
\hline & $C_{4}$ & {$[\mathrm{~K}]$} & $1.0205 \cdot 10^{3}$ & $1.3629 \cdot 10^{3}$ & $5.0059 \cdot 10^{1}$ & $2.5661 \cdot 10^{-5}$ \\
\hline \multirow[t]{4}{*}{ isotropic hardening } & $C_{13}$ & {$\left[\mathrm{~m}^{2} / \mathrm{N}\right]$} & $1.5467 \cdot 10^{-6}$ & $3.7854 \cdot 10^{-5}$ & $6.1469 \cdot 10^{-4}$ & $1.9986 \cdot 10^{-4}$ \\
\hline & $C_{14}$ & {$[\mathrm{~K}]$} & $3.1400 \cdot 10^{3}$ & $6.8995 \cdot 10^{3}$ & $9.9999 \cdot 10^{3}$ & $4.4629 \cdot 10^{3}$ \\
\hline & $C_{15}$ & {$\left[\mathrm{~N} / \mathrm{m}^{2}\right]$} & $5.4853 \cdot 10^{7}$ & $2.3658 \cdot 10^{7}$ & $9.5593 \cdot 10^{7}$ & $2.2665 \cdot 10^{8}$ \\
\hline & $C_{16}$ & {$[\mathrm{~K}]$} & $9.5639 \cdot 10^{2}$ & $1.2071 \cdot 10^{3}$ & $9.3357 \cdot 10^{2}$ & $4.5834 \cdot 10^{1}$ \\
\hline \multirow[t]{4}{*}{ strain rate sensitivity } & $C_{1}$ & {$\left[\mathrm{~N} / \mathrm{m}^{2}\right]$} & $2.3445 \cdot 10^{7}$ & $5.4241 \cdot 10^{6}$ & $3.6396 \cdot 10^{7}$ & $6.1235 \cdot 10^{6}$ \\
\hline & $C_{2}$ & {$[\mathrm{~K}]$} & $1.1769 \cdot 10^{-3}$ & $4.9720 \cdot 10^{-3}$ & $7.2511 \cdot 10^{-1}$ & $9.5004 \cdot 10^{-2}$ \\
\hline & $C_{5}$ & {$[1 / \mathrm{s}]$} & $7.7219 \cdot 10^{-1}$ & $2.3260 \cdot 10^{-3}$ & $1.0000 \cdot 10^{3}$ & $4.8469 \cdot 10^{3}$ \\
\hline & $C_{6}$ & {$[\mathrm{~K}]$} & $1.9439 \cdot 10^{1}$ & $5.0000 \cdot 10^{2}$ & $9.9999 \cdot 10^{3}$ & $8.8351 \cdot 10^{3}$ \\
\hline
\end{tabular}


Table 7 Identified parameters of the EMMI model

\begin{tabular}{|c|c|c|c|c|c|c|}
\hline & & & $16 \mathrm{MnCr} 5$ & $\mathrm{C} 15$ & $50 / 51 \mathrm{CrV} 4$ & AlMgSi1 \\
\hline \multirow[t]{5}{*}{ initial yield stress } & $\breve{m}_{1}$ & {$[-]$} & $2.2039 \cdot 10^{-3}$ & $2.0614 \cdot 10^{-4}$ & $5.8995 \cdot 10^{-4}$ & $5.0753 \cdot 10^{-3}$ \\
\hline & $\breve{m}_{2}$ & {$[-]$} & $1.5474 \cdot 10^{0}$ & $1.8729 \cdot 10^{1}$ & $2.3324 \cdot 10^{-2}$ & $4.8819 \cdot 10^{-2}$ \\
\hline & $\breve{m}_{3}$ & {$[-]$} & $1.0657 \cdot 10^{-4}$ & $2.4278 \cdot 10^{0}$ & $3.8739 \cdot 10^{0}$ & $4.0010 \cdot 10^{0}$ \\
\hline & $\breve{m}_{4}$ & {$[-]$} & $3.3609 \cdot 10^{0}$ & $8.0903 \cdot 10^{0}$ & $1.9781 \cdot 10^{0}$ & $1.8999 \cdot 10^{0}$ \\
\hline & $\breve{m}_{5}$ & {$[-]$} & $4.8292 \cdot 10^{-1}$ & $9.5687 \cdot 10^{-1}$ & $3.3124 \cdot 10^{-1}$ & $2.7153 \cdot 10^{-3}$ \\
\hline \multirow[t]{3}{*}{ isotropic hardening } & $\breve{c}_{5}$ & {$[-]$} & $2.5853 \cdot 10^{1}$ & $1.5349 \cdot 10^{2}$ & $1.0593 \cdot 10^{2}$ & $6.8426 \cdot 10^{-2}$ \\
\hline & $\breve{c}_{6}$ & {$[-]$} & $4.7002 \cdot 10^{-4}$ & $1.0311 \cdot 10^{-3}$ & $4.2656 \cdot 10^{-4}$ & $8.7748 \cdot 10^{-4}$ \\
\hline & $\breve{Q}_{3}$ & {$[-]$} & $1.2826 \cdot 10^{0}$ & $6.2111 \cdot 10^{-1}$ & $2.1526 \cdot 10^{0}$ & $1.6437 \cdot 10^{0}$ \\
\hline \multirow[t]{4}{*}{ strain rate sensitivity } & $\breve{c}_{1}$ & {$[-]$} & $1.4447 \cdot 10^{-2}$ & $2.0296 \cdot 10^{-1}$ & $1.4699 \cdot 10^{0}$ & $1.3858 \cdot 10^{-2}$ \\
\hline & $\breve{c}_{2}$ & {$[-]$} & $1.0004 \cdot 10^{-5}$ & $1.3333 \cdot 10^{-1}$ & $6.6782 \cdot 10^{1}$ & $5.1449 \cdot 10^{-7}$ \\
\hline & $\breve{c}_{9}$ & {$[-]$} & $1.1418 \cdot 10^{0}$ & $3.9766 \cdot 10^{-1}$ & $3.4616 \cdot 10^{-2}$ & $2.3568 \cdot 10^{0}$ \\
\hline & $\breve{Q}_{1}$ & {$[-]$} & $4.1991 \cdot 10^{0}$ & $1.1109 \cdot 10^{1}$ & $1.5825 \cdot 10^{1}$ & $4.3542 \cdot 10^{0}$ \\
\hline
\end{tabular}

approximation of dissipated work into heat, the temperature increase $\dot{\theta}>0$ is determined by:

$\dot{\theta}=\frac{\gamma_{\mathrm{TQ}}}{\rho c_{v}}\left(\mathbf{T} \cdot \mathbf{D}_{\mathrm{pl}}\right)$

The specific heat capacity $c_{v}$ is chosen for the steel alloys with a typical value of $450 \mathrm{~J} /(\mathrm{kg} \mathrm{K})$ and for aluminium with $896 \mathrm{~J} /(\mathrm{kg} \mathrm{K})$. The TAYLOR-QUINNEY coefficient $\gamma_{\mathrm{TQ}}$ is set to 0.90 for the BCJ and the EMMI model. In the proposed model the temperature increases due to energy storage or dissipation in each rheological element leading to a better prediction of the energy storage behaviour (see [5], and [7]) during the entire strain process without the need of the TAYLOR-QUINNEY coefficient.

As already mentioned in Section "Thermo-viscoplastic material models", the normalisation of the constitutive equations of the EMMI model requires a total of five material constants and constitutive variables. Due to the lack of these parameters for the materials investigated, all of the parameters for the normalisation are taken from the reference [14] p. 43. Thereby, the parameters for the investigated steel types are normalised with the values of the steel SS304L. The applied model parameters for the non-dimensional EMMI model for steel and aluminium are summarised in Table 5.

The 10 identified parameters of the BCJ model are found in Table 6 for the case hardening steel $16 \mathrm{MnCr} 5$, the low carbon steel $\mathrm{C} 15$, the low alloy steel 50/51CrV4, and the aluminium alloy AlMgSi1. The 12 moduli of the EMMI model are composed in Table 7 and the 11 model parameters of the proposed model are listed in Table 8 .

The constitutive parameters of the proposed model are already identified by means of the test data for the low alloy steel 50/51CrV4 in [4]. Thereby, all possible model features are applied and, as a result, the identified model parameters used in [4] differ from the model parameters applied in this contribution.

Table 8 Identified parameters of the proposed model

\begin{tabular}{|c|c|c|c|c|c|c|}
\hline & & & $16 \mathrm{MnCr} 5$ & $\mathrm{C} 15$ & $50 / 51 \mathrm{CrV} 4$ & AlMgSi1 \\
\hline \multirow[t]{3}{*}{ initial yield stress } & $\kappa_{0}$ & {$\left[N / m^{2}\right]$} & $2.7062 \cdot 10^{8}$ & $3.8056 \cdot 10^{8}$ & $3.0760 \cdot 10^{8}$ & $1.7211 \cdot 10^{7}$ \\
\hline & $Q_{\kappa_{0}}$ & {$[1 / \mathrm{K}]$} & $7.9930 \cdot 10^{-3}$ & $6.8182 \cdot 10^{-3}$ & $4.3179 \cdot 10^{-3}$ & $9.3016 \cdot 10^{-3}$ \\
\hline & $\theta_{\kappa_{0}}$ & {$[\mathrm{~K}]$} & $9.4798 \cdot 10^{2}$ & $8.1849 \cdot 10^{2}$ & $7.8636 \cdot 10^{2}$ & $6.5469 \cdot 10^{2}$ \\
\hline \multirow[t]{4}{*}{ isotropic hardening } & $E_{\kappa}$ & {$\left[N / m^{2}\right]$} & $3.1017 \cdot 10^{9}$ & $2.3334 \cdot 10^{9}$ & $1.6074 \cdot 10^{9}$ & $2.0455 \cdot 10^{8}$ \\
\hline & $Q_{\kappa}$ & {$[1 / \mathrm{K}]$} & $1.8797 \cdot 10^{-3}$ & $4.9547 \cdot 10^{-3}$ & $2.5268 \cdot 10^{-3}$ & $2.0780 \cdot 10^{-2}$ \\
\hline & $\theta_{\kappa}$ & {$[\mathrm{K}]$} & $8.6949 \cdot 10^{2}$ & $1.2060 \cdot 10^{3}$ & $7.0049 \cdot 10^{2}$ & $6.6815 \cdot 10^{2}$ \\
\hline & $\varepsilon_{\kappa}^{\infty}$ & {$[-]$} & $1.3488 \cdot 10^{-1}$ & $1.3370 \cdot 10^{-1}$ & $1.5817 \cdot 10^{-1}$ & $1.6854 \cdot 10^{-1}$ \\
\hline \multirow[t]{4}{*}{ strain rate sensitivity } & $\eta$ & {$[\mathrm{s}]$} & $3.6961 \cdot 10^{2}$ & $2.5912 \cdot 10^{2}$ & $6.5155 \cdot 10^{2}$ & $2.0493 \cdot 10^{1}$ \\
\hline & $Q_{\eta}$ & {$[\mathrm{K}]$} & $7.2394 \cdot 10^{3}$ & $3.7554 \cdot 10^{3}$ & $3.9329 \cdot 10^{2}$ & $1.9705 \cdot 10^{4}$ \\
\hline & $m_{0}$ & {$[-]$} & $2.1947 \cdot 10^{0}$ & $1.8214 \cdot 10^{0}$ & $1.1712 \cdot 10^{0}$ & $2.5437 \cdot 10^{0}$ \\
\hline & $m_{1}$ & {$[\mathrm{~K}]$} & $1.1852 \cdot 10^{3}$ & $1.0149 \cdot 10^{3}$ & $3.9728 \cdot 10^{3}$ & $4.1466 \cdot 10^{3}$ \\
\hline
\end{tabular}




\section{Evaluation and critical review of material models by means of stress-strain curves}

A crucial criterion for the assessment of a viscoplastic model is the close agreement of best simulation results for the chosen parameters with the test data. Therefore, the predicted stress-strain curves of the three investigated models are compared to test data of various forming steel types such as for the steel alloys $16 \mathrm{MnCr} 5, \mathrm{C} 15$, 50/51CrV4 and the special aluminium alloy AlMgSi1. Note, the negative CAUCHY stress component (also called true stress) and the negative HENCKY strain component (also called logarithmic or true strain) are presented without the algebraic sign in the following diagrams as given typically in the experimental database of compression tests. All of the simulation results are shown as stress-strain curves with
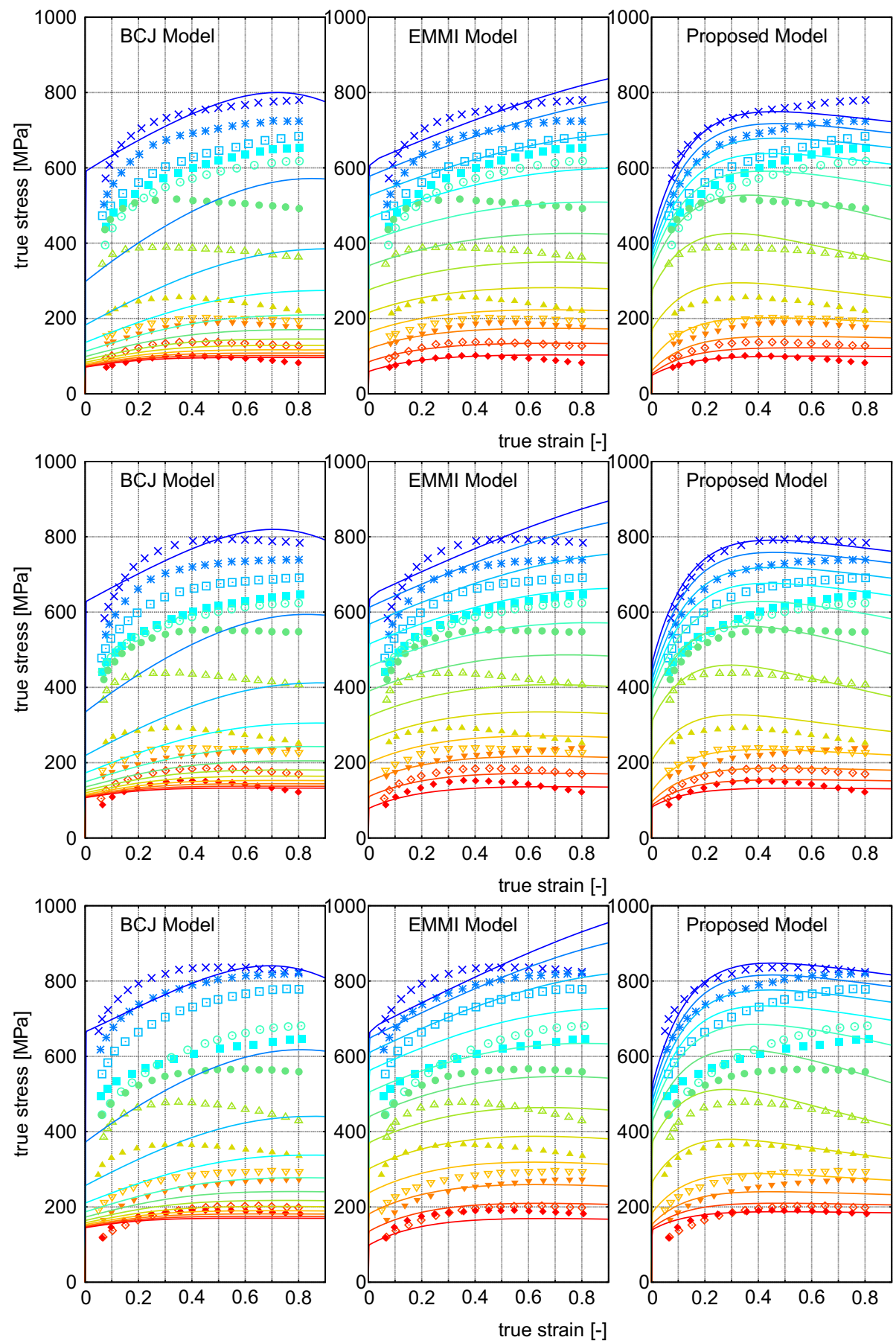

Fig. 7 Test data (dots) and simulation results (lines) of $16 \mathrm{MnCr} 5$ for strain rates $\dot{\varepsilon}=1.61 / \mathrm{s}, 8.01 / \mathrm{s}, 401 / \mathrm{s}$ strain rate $1.61 \mathrm{~s}$

\begin{tabular}{|rrrr|}
\hline \multicolumn{4}{|c|}{ temperature [K] } \\
\hline 293 & $\times$ & 873 & $\Delta$ \\
373 & $*$ & 973 & $\Delta$ \\
473 & $\square$ & 1073 & $\nabla$ \\
573 & $\square$ & 1173 & $\vee$ \\
673 & $\odot$ & 1273 & $\diamond$ \\
773 & $\bullet$ & 1373 & $\bullet$ \\
\hline
\end{tabular}

strain rate $8.01 \mathrm{~s}$

strain rate $40.01 \mathrm{~s}$

\begin{tabular}{|rrrr|}
\hline \multicolumn{4}{|c|}{ temperature [K] } \\
\hline 293 & $\times$ & 873 & $\Delta$ \\
373 & $*$ & 973 & $\Delta$ \\
473 & $\bullet$ & 1073 & $\nabla$ \\
573 & $\mathbf{1}$ & 1173 & $\nabla$ \\
673 & $\odot$ & 1273 & $\diamond$ \\
773 & $\bullet$ & 1373 & $\bullet$ \\
\hline
\end{tabular}


solid lines, whereas the test data are shown as dots in the view graphs below.

The response of the three material models investigated are compared to the test data of the case hardening steel $16 \mathrm{MnCr} 5$ at the true strain rate of $1.61 / \mathrm{s}, 8.01 / \mathrm{s}$ and $40.0 \mathrm{1} / \mathrm{s}$ in Fig. 7. The test data with a temperature of $293 \mathrm{~K}$ and $1373 \mathrm{~K}$ is in good agreement with the simulation result of the $\mathrm{BCJ}$ model. However, the temperature range in between is insufficiently predicted, so that the $\mathrm{BCJ}$ material model is barely suitable for a forging analysis comprising the entire range from room temperature up to values close to the melting point. The EMMI model describes the experimental data in the entire range of temperature well, even though the hardening behaviour at $293 \mathrm{~K}$ is not predicted precisely. A possible reason for the poor prediction accuracy is the absence of a temperature
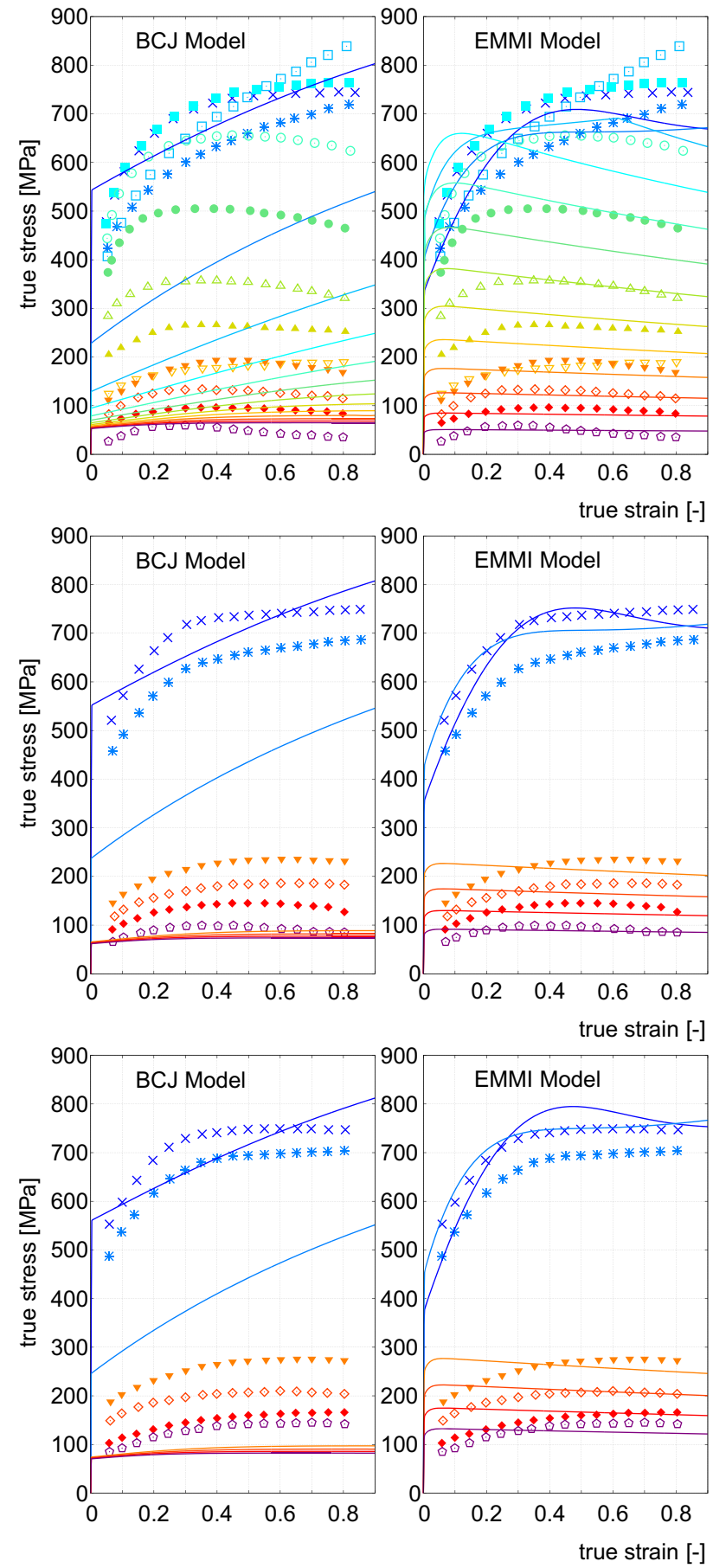

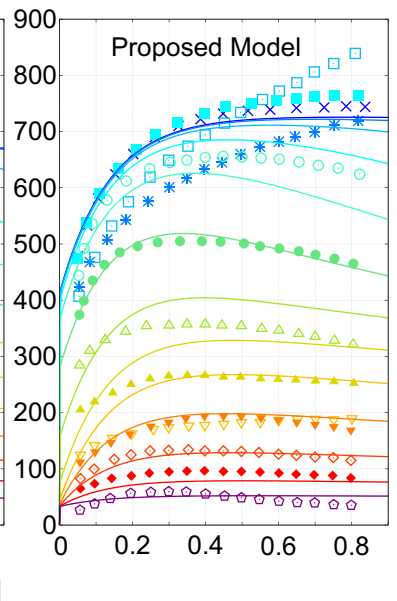

strain rate $1.61 \mathrm{~s}$

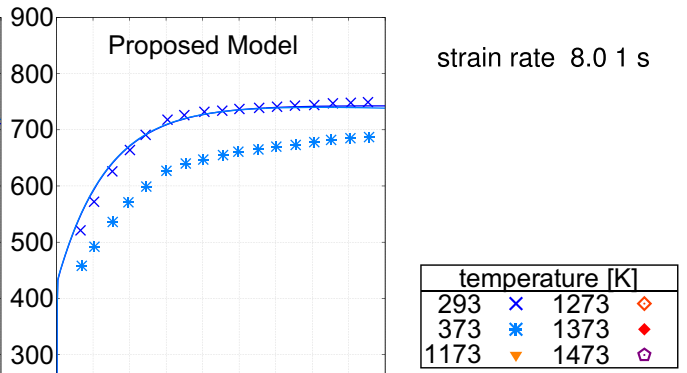

\begin{tabular}{|cccc}
\hline \multicolumn{4}{|c|}{ temperature [K] } \\
\hline 293 & $\times$ & 973 & $\Delta$ \\
373 & $*$ & 1073 & $\nabla$ \\
473 & - & 1173 & $\vee$ \\
573 & $\square$ & 1273 & $\diamond$ \\
673 & $\odot$ & 1373 & $\bullet$ \\
773 & $\bullet$ & 1473 & $\bullet$ \\
873 & $\triangle$ & & \\
\hline
\end{tabular}
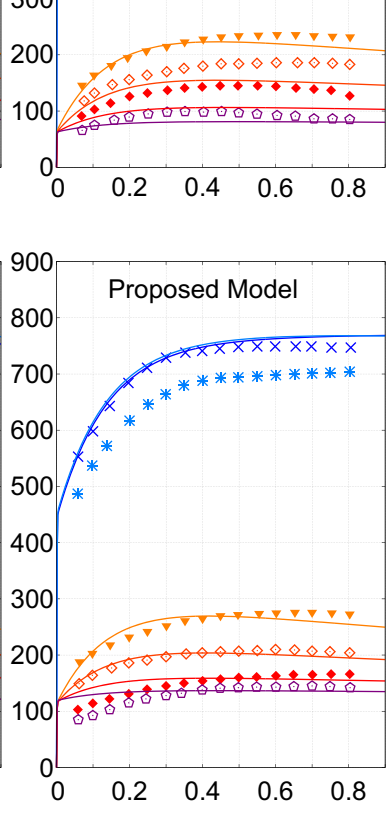

strain rate $40.01 \mathrm{~s}$

\begin{tabular}{|cccc|}
\hline \multicolumn{5}{|c|}{ temperature [K] } \\
\hline 293 & $\times$ & 1273 & $\diamond$ \\
373 & $*$ & 1373 & \\
1173 & $\vee$ & 1473 & $\bullet$ \\
\hline
\end{tabular}

Fig. 8 Test data (dots) and simulation results (lines) of C15 for strain rates $\dot{\varepsilon}=1.6$ 1/s, 8.0 1/s, 40 1/s 

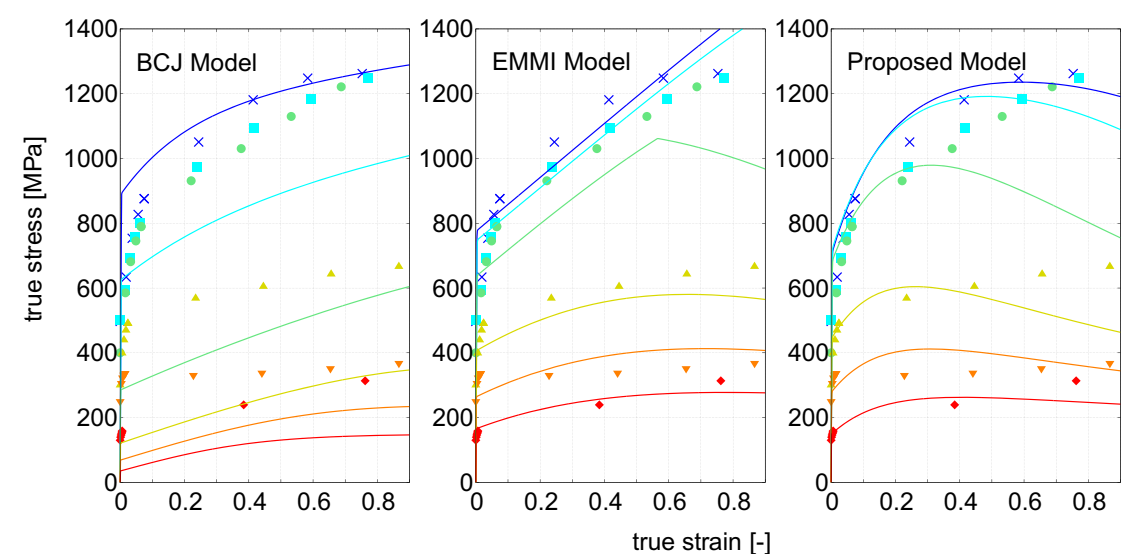

strain rate $0.0251 / \mathrm{s}$
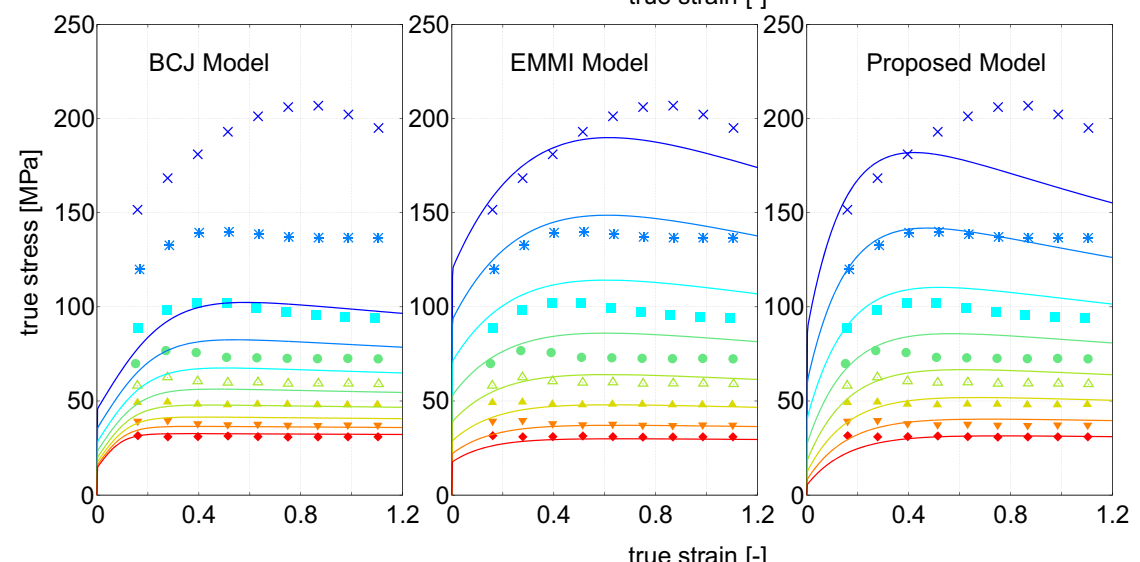

strain rate $0.11 / \mathrm{s}$

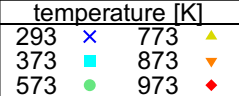

573 - 973
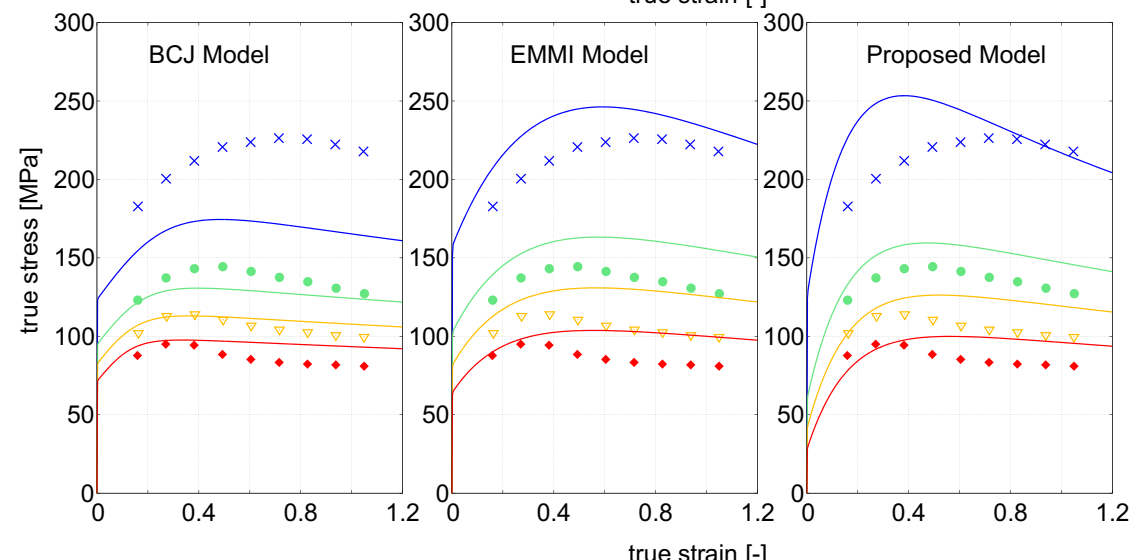

strain rate $1.01 / \mathrm{s}$
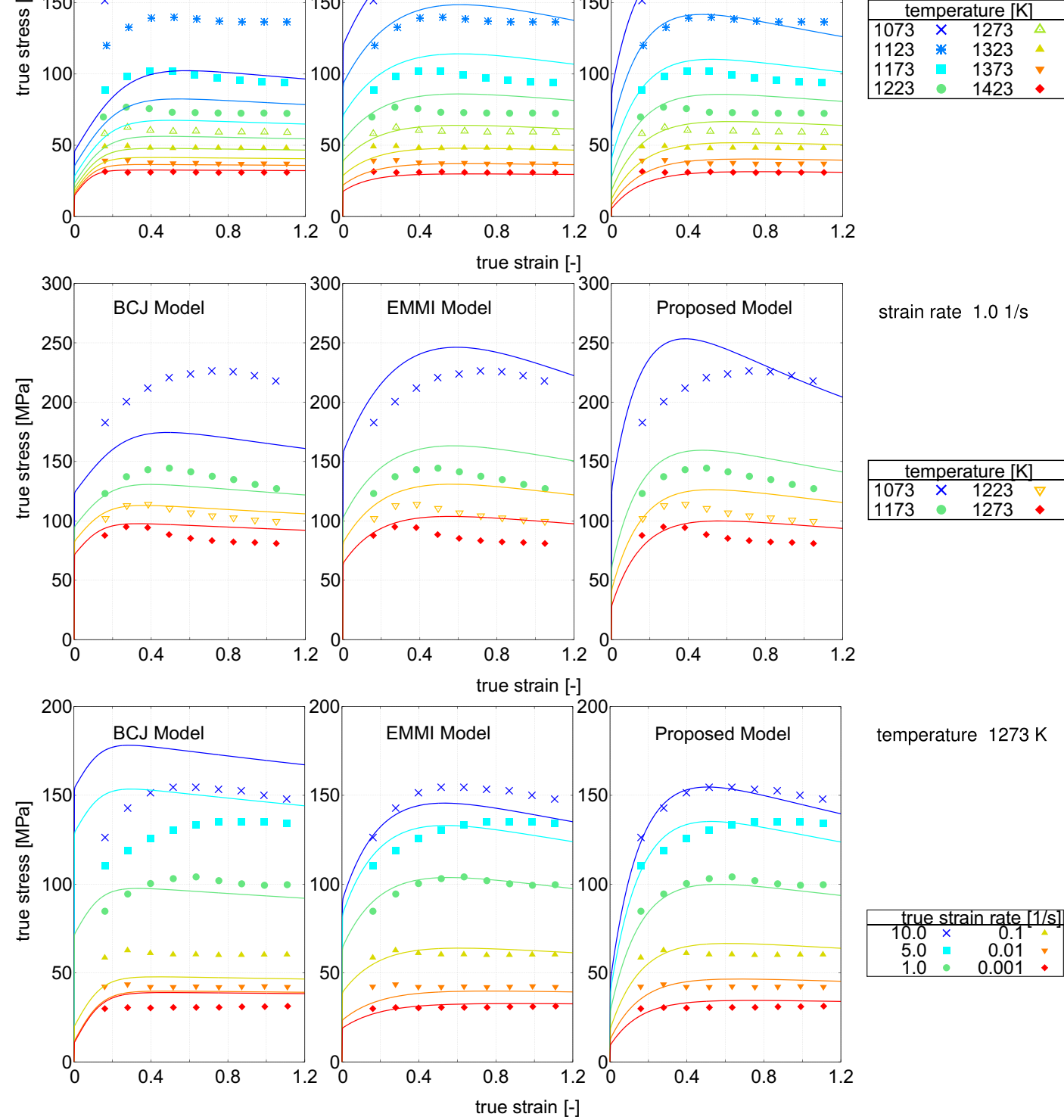

temperature $1273 \mathrm{~K}$

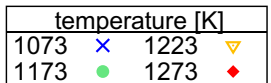

$1173 \times 1273$

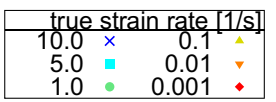

Fig. 9 Test data (dots) and simulation results (lines) of $50 \mathrm{CrV} 4 / 51 \mathrm{CrV} 4$ for strain rates $\dot{\varepsilon}=0.0251 / \mathrm{s}, 0.11 / \mathrm{s}, 1.01 / \mathrm{s}$ and temperature $\theta=1273 \mathrm{~K}$ 
dependent hardening modulus (see Table 3). However, the simulation result with the proposed model shows a fairly good agreement with the test data over the entire range of chosen temperatures. Furthermore, it describes the hardening behaviour at low temperatures better than the EMMI model.

For the low carbon steel C15, the comparison between the simulation results is shown for the three material models and the test data at the true strain rate of $1.61 / \mathrm{s}$, $8.0 \mathrm{1} / \mathrm{s}$ and $40.0 \mathrm{1} / \mathrm{s}$ in Fig. 8. The BCJ model captures acceptably well the flow curves of the test data at $293 \mathrm{~K}$ and $1473 \mathrm{~K}$. However, the prediction of the temperature range between those temperatures is unsatisfactory. A good agreement between the test data and the simulation results with the EMMI model is achieved at the temperature levels of $273 \mathrm{~K}$ as well as from $773 \mathrm{~K}$ up to $1473 \mathrm{~K}$. The
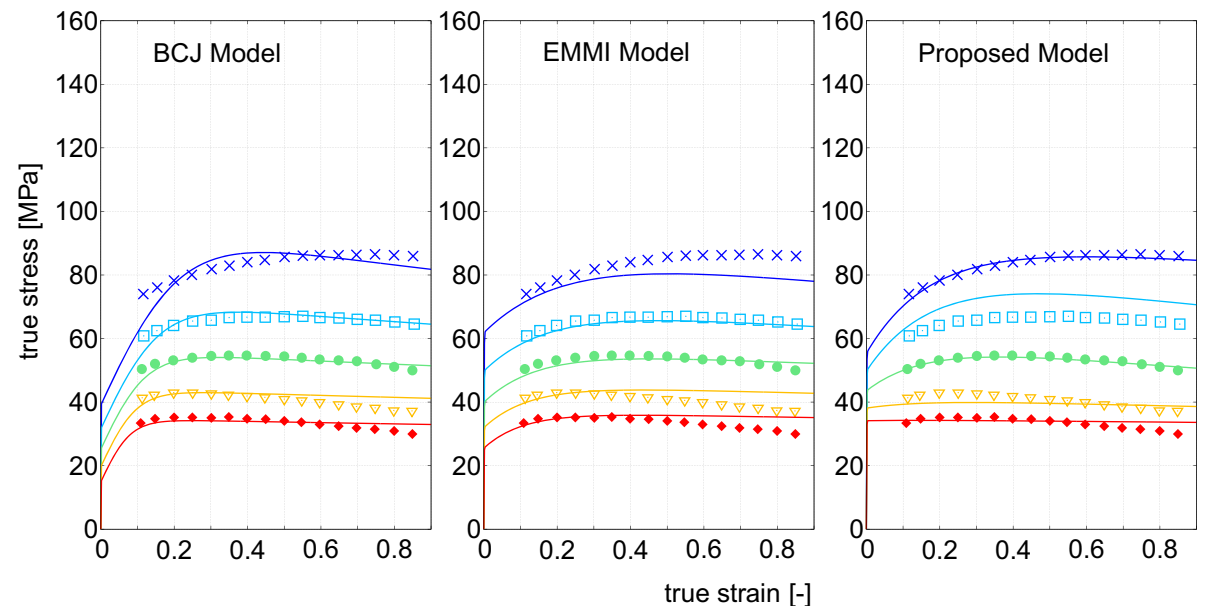

strain rate $0.31 \mathrm{~s}$
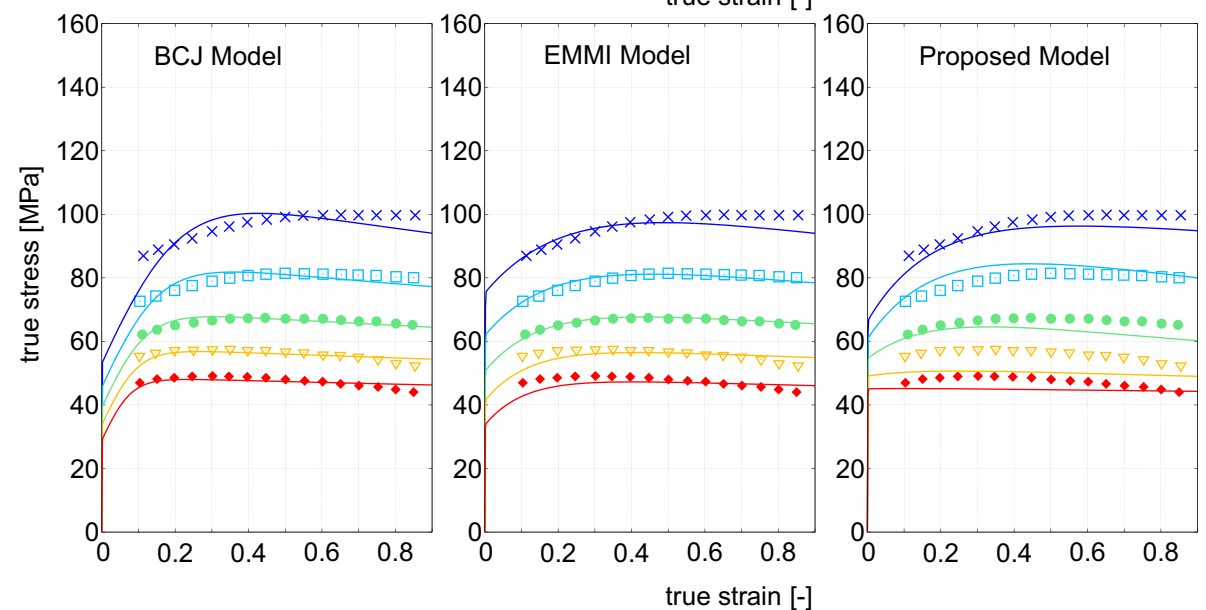

strain rate $3.01 \mathrm{~s}$
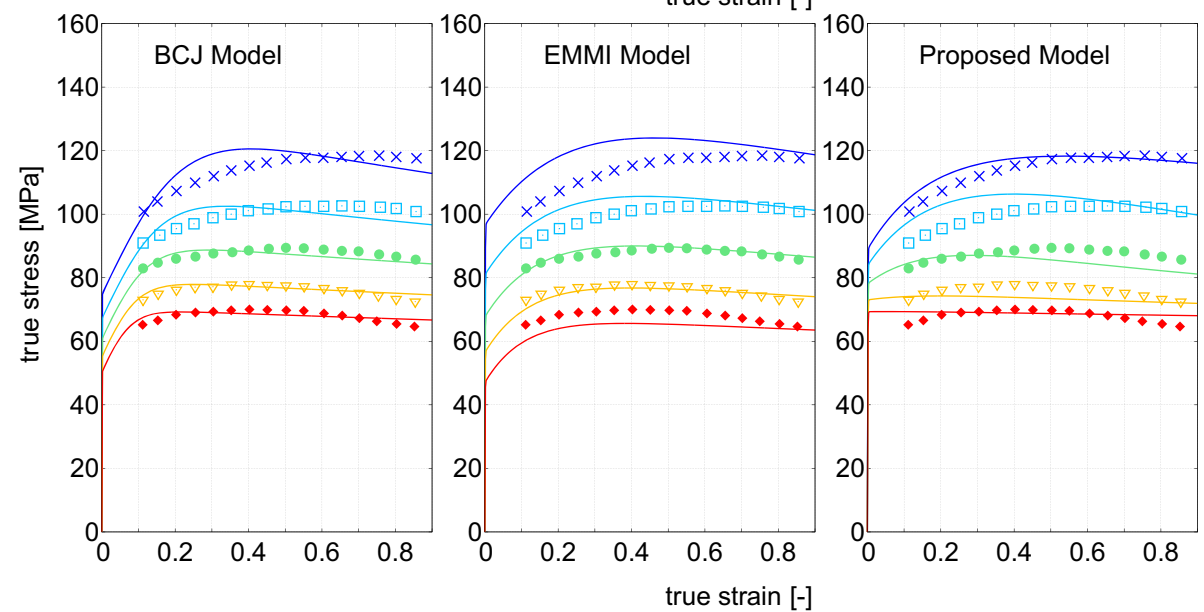

strain rate $100.01 \mathrm{~s}$

\begin{tabular}{|c|c|c|c|}
\hline \multicolumn{4}{|c|}{ temperature [K] } \\
\hline 573 & $x$ & 723 & $\nabla$ \\
\hline 623 & ๑ & $7 \overline{73}$ & - \\
\hline 673 & 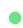 & & \\
\hline
\end{tabular}

\begin{tabular}{|cccc|}
\hline \multicolumn{4}{|c|}{ temperature [K] } \\
\hline 573 & $\times$ & 723 & $\nabla$ \\
623 & $\square$ & 773 & \\
673 & $\bullet$ & & \\
\hline
\end{tabular}

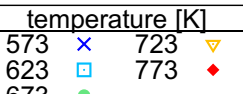

$623 \square 773$

673

Fig. 10 Test data (dots) and simulation results (solid lines) of AlMgSi1 for strain rates $\dot{\varepsilon}=0.3$ 1/s, 3.0 1/s, 100 1/s 
Table 9 Averaged MSE values $\epsilon_{\mathrm{MSE} \text {, ave }}$ (in $10^{-3}$ ) of investigated metals and material models

\begin{tabular}{llll}
\hline & BCJ Model & EMMI Model & Proposed Model \\
\hline $16 \mathrm{MnCr} 5$ & 876.33 & 8.04 & 7.29 \\
$\mathrm{C} 15$ & 197.97 & 17.98 & 14.94 \\
$50 / 51 \mathrm{CrV} 4$ & 70.29 & 10.55 & 10.38 \\
AlMgSi1 & 0.99 & 2.09 & 2.61 \\
\hline
\end{tabular}

proposed model's results are close to the test data even at the aforementioned temperature levels. Nevertheless, all of the simulation results with the investigated material models show a strong deviation from the test data in the temperature range of $373 \mathrm{~K}$ to $673 \mathrm{~K}$. Here, the yield stress increases with temperature in contrast to the decrease below and above this range. The reason of the increase is the so called blue brittleness, which occurs for this steel type with the characteristic blue colour at approximately $473 \mathrm{~K}$ to $673 \mathrm{~K}$. Within this temperature range, nitrogen atoms diffuse into dislocation regions and block dislocation motions leading to increasing yield stress. Due to this anomaly of the C15 steel, its behaviour in the blue brittleness range is predicted well by any of the material models under consideration.

The simulation results with the BCJ model, the EMMI model, and the proposed model are compared to the test data of the low alloy steel $51 \mathrm{CrV} 4$ at the engineering strain rate of $0.0251 / \mathrm{s}$ and temperature range from $293 \mathrm{~K}$ to $973 \mathrm{~K}$ in Fig. 9, first row. Numerical results are compared to test data of the alloy $50 \mathrm{CrV} 4$ at temperature levels from $1073 \mathrm{~K}$ to $1423 \mathrm{~K}$ at the true strain rate of $0.11 / \mathrm{s}$ in Fig. 9, second row. A comparison at the true strain rate $1.01 / \mathrm{s}$ is shown in the third row of Fig. 9 for temperatures from $1073 \mathrm{~K}$ to $1423 \mathrm{~K}$ and in the fourth row for a constant temperature of $1273 \mathrm{~K}$ at true strain rates between 0.001 and $10.01 / \mathrm{s}$. The simulation results of the BCJ model are in good agreement with the test data at $293 \mathrm{~K}$ and at $1423 \mathrm{~K}$. However, the exponential approach of the course of the initial yield stress versus temperature leads to an insufficient reproduction of the yield behaviour in the intermediate temperature region. Hence, the BCJ model is not suitable for the application to hot/cold forging in the entire temperature range. Using the EMMI model, the simulation results are in good agreement with the experimental data in the complete temperature range. Nevertheless, the hardening behaviour at low temperature is not predicted precisely since, again, no temperature dependent hardening modulus is applied (see Table 3). The proposed model predicts the test data very well in the entire temperature range, whereby the hardening behaviour at low temperature values is captured more accurately than with the EMMI model.

For the aluminium alloy AlMgSi1, the model's performance is shown by means of the simulation results and the test data at the true strain rate $0.31 / \mathrm{s}, 3.01 / \mathrm{s}$ and $100.01 / \mathrm{s}$ in Fig. 10. For all strain rates, the temperature is only given for hot forging analyses. The experimental data is reproduced acceptably well in the entire temperature range with the BCJ model. However, the hardening is too strong immediately after yielding initiates, compared to the test data at hand. Nevertheless, the BCJ model is suitable to capture the mechanical behaviour under deformation of AlMgSi1 in the hot forging temperature range. The simulation results of the EMMI and proposed model lead to a satisfactory agreement with the experimentally measured stress.

To evaluate the material models quantitatively, the MSE is calculated between the predicted stress-strain curves and the test data for each load case for a load case for a specific temperature level and a strain rate. Afterwards, the MSE values are averaged for critical assessment to a value of

$\epsilon_{\mathrm{MSE}, \text { ave }}=\frac{1}{m} \sum_{j=1}^{m} \epsilon_{\mathrm{MSE}, j}$.

Thereby, $m$ is the number of load cases. The averaged MSE values $\epsilon_{\mathrm{MSE}}$,ave are summarised for each material model and metal type under investigation in Table 9 and depicted as bar diagram in Fig. 11 for a graphical interpretation.

Note, the averaged MSE values of the BCJ model are the highest ones for all steel types considered. Hence, this material model is barely suitable to describe the mechanical response under deformation tested in a large range of different temperatures. Significant better results are produced by the EMMI model than with the BCJ proposed.

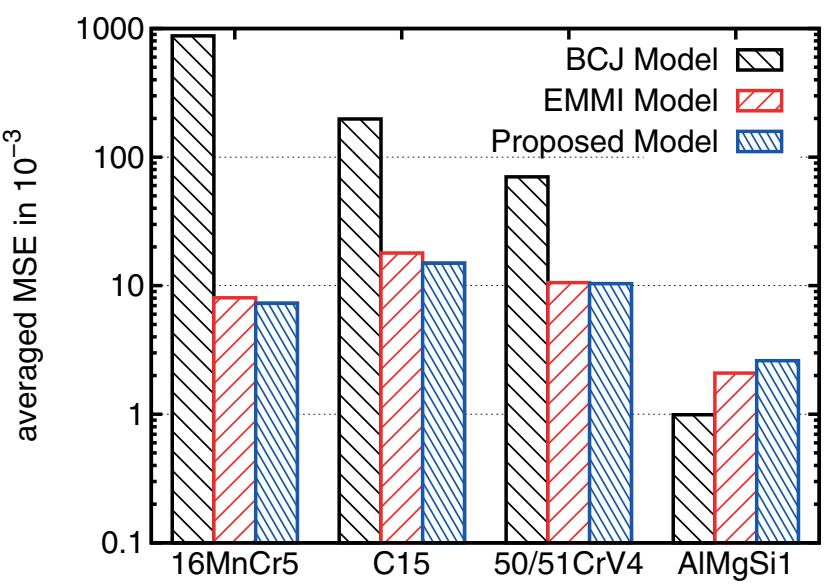

Fig. 11 Bar diagram of the averaged MSE values $\epsilon_{\mathrm{MSE} \text {,ave }}$ of the investigated metals and material models 


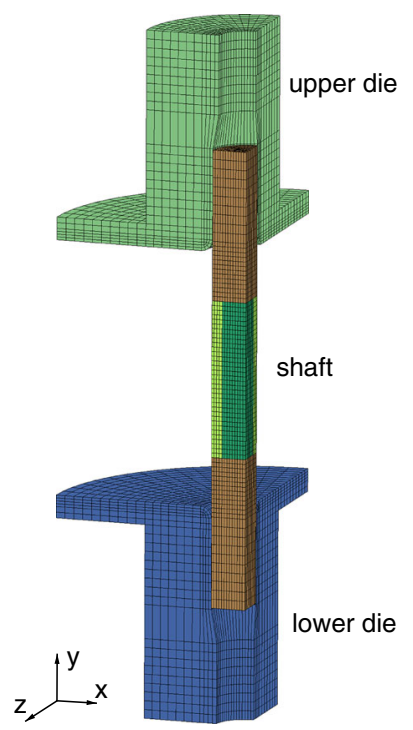

Fig. 12 FE model of experimental setup for hot/cold forging analysis

Consequently, the numerical results from the EMMI model show a lower MSE of approximately one order of magnitude compared to the one of the BCJ model. Hence, the EMMI model is suitable to predict the mechanical behaviour under deformation of the forming metals investigated within the complete temperature range. The application of the proposed model causes the lowest MSE values and, therefore, it is best suited to represent the mechanical response under deformation in the large temperature range of simultaneous hot/cold forging processes. Comparing its averaged MSE values to the ones of the EMMI model, the proposed model improves the accuracy of about $9 \%$ for the alloy $16 \mathrm{MnCr} 5$ and of $17 \%$ for the $\mathrm{C} 15$ steel. The improvement for $50 / 51 \mathrm{CrV} 4$ is approximately $2 \%$. For the aluminium alloy AlMgSi1, its MSE is slightly higher than the one of the EMMI model, but still in a very good range. In view of the poor accuracy of the BCJ model for the steel alloys at hand, the identification of its ten parameters is of high effort. The EMMI model uses twelve parameters in total and achieves significant better simulation results. The proposed model predicts the stress-strain curves between room temperature and close to the melting point best, whereby eleven parameters are needed.

\section{Model validation by $\mathrm{FE}$ analysis of simultaneous hot/cold forging of a shaft}

The simultaneous hot/cold forging process, discussed in Section "Simultaneous hot/cold forging of a gear shaft", comprises three different steps: heating, forging, and final cooling. This chapter focuses on the FE analysis of the forging process with the three different material models above. First, the modelling of the heating process is explained briefly to generate the final temperature field prior to the forging step. The cooling process is not considered here due to the lack of phase transformation description in the material models investigated. Therefore, a prediction of the microstructure is not possible with any of these models. A detailed FE analysis of the complete forging process is given in [17], [15], [16], and [8].

Due to symmetry, only a quarter of the experimental setup is modelled for the FE simulation (see Fig. 12). The upper and lower die undergo relatively small deformations and, therefore, are described as rigid bodies. Eight-node solid elements are used for the spatial discretisation. The middle of the shaft undergoes large deformations during
Table 10 Temperature dependent thermal material parameters of the steel alloy for the shaft $51 \mathrm{CrV} 4$ and the die $\mathrm{X} 38 \mathrm{CrMoV} 5$ (taken from [16])

\begin{tabular}{|c|c|c|c|}
\hline \multicolumn{4}{|l|}{$51 \mathrm{CrV} 4$ (shaft) } \\
\hline specific heat capacity & $\frac{\mathrm{J}}{\mathrm{kg} \mathrm{K}}$ & $c_{p}(\theta=300 \mathrm{~K})$ & 450 \\
\hline \multirow{3}{*}{ thermal conductivity } & \multirow{3}{*}{$\frac{\mathrm{W}}{\mathrm{m} \mathrm{K}}$} & $c_{p}(\theta=1500 \mathrm{~K})$ & 750 \\
\hline & & $k(\theta=300 \mathrm{~K})$ & 47 \\
\hline & & $k(\theta=1100 \mathrm{~K})$ & 25 \\
\hline \multirow{3}{*}{ thermal expansion coefficient } & \multirow{3}{*}{$\frac{1}{\mathrm{~K}}$} & $k(\theta=1500 \mathrm{~K})$ & 28 \\
\hline & & $\alpha(\theta=300 \mathrm{~K})$ & $1.0 \cdot 10^{-5}$ \\
\hline & & $\alpha(\theta=1400 \mathrm{~K})$ & $1.6 \cdot 10^{-5}$ \\
\hline \multicolumn{4}{|l|}{ X38CrMoV5-1 (die) } \\
\hline specific heat capacity & $\frac{\mathrm{J}}{\mathrm{kg} \mathrm{K}}$ & $c_{p}(\theta=300 \mathrm{~K})$ & 425 \\
\hline & $\mathrm{W}$ & $c_{p}(\theta=800 \mathrm{~K})$ & 650 \\
\hline thermal conductivity & $\frac{\mathrm{v}}{\mathrm{m} \mathrm{K}}$ & $k$ & 25 \\
\hline
\end{tabular}


Fig. 13 Initial temperature field (in $\mathrm{K}$ ) of the forging process for the EMMI and proposed model (left plot) and the BCJ model (right plot) and temperature course along the shaft

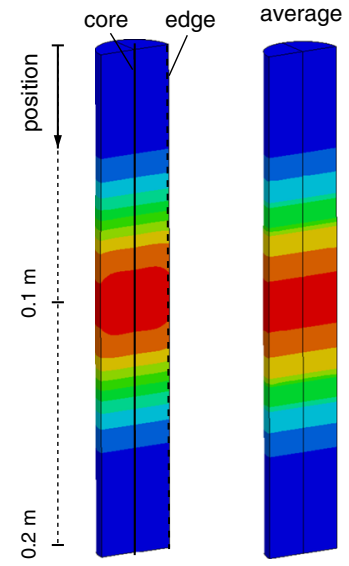

Fringe Levels $1.490 e+03$ $1.371 e+03$ $1.252 \mathrm{e}+03$ $1.133 \mathrm{e}+03$ $1.014 \mathrm{e}+03$ $8.950 e+02$ $7.760 \mathrm{e}+02$ $6.570 \mathrm{e}+02$ $5.380 e+02$ $4.190 \mathrm{e}+02$ $3.000 e+02$

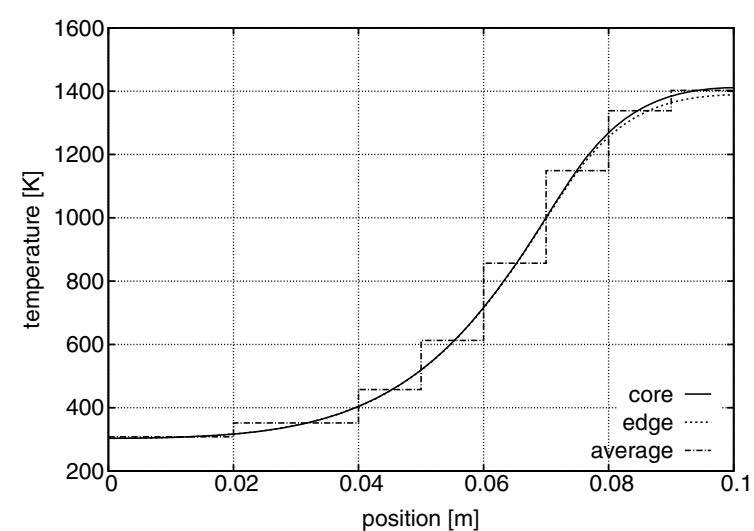

the forging process. Thus, the shaft is discretised with reduced integrated eight-node solid elements (constantstress elements) with hourglass control in LS-DYNA.

\section{Inductive heating}

The modelling of inductive heating requires an electromagnetic-thermo-mechanical coupled approach. However, the analysis of this multi field coupled problem is very time consuming and cost intensive. Therefore, only a thermo-mechanical coupled simulation is chosen here for the inductive heating by means of volumetric heat sources. Furthermore, free convection at the surfaces is taken into account leading to heat loss in the shaft. The temperature dependent constitutive parameters for the shaft steel 51CrV4 and the tool steel X38CrMoV5 are taken from [16], shown for the sake of convenience in Table 10.
The complete heating process with positioning of the shaft in the tools lasts 23.8 seconds. Due to the long time period, this step is analysed by a thermomechanical coupled simulation with an implicit solver for the mechanical and thermal field allowing comparatively large time steps. During the heating process, the temperature increases rapidly in the middle section of the shaft, while the displacement field changes hardly with time. Therefore, the thermal time step size is set to 0.1 seconds and, thus, much smaller than the mechanical time step size with 1.0 second. The temperature field of the shaft evolves during the heating process and after positioning of the shaft in the dies as shown in [16] p. 285, Fig. 14.

In a previous analysis of the heating, forging, and cooling step in a single simulation, LS-DYNA ignores the temperature increase due to the inductive heating with the BCJ and EMMI model. However, it is possible to apply
Fig. 14 Effective plastic strain at the end of the hot/cold forging step with detailed view in the flange area

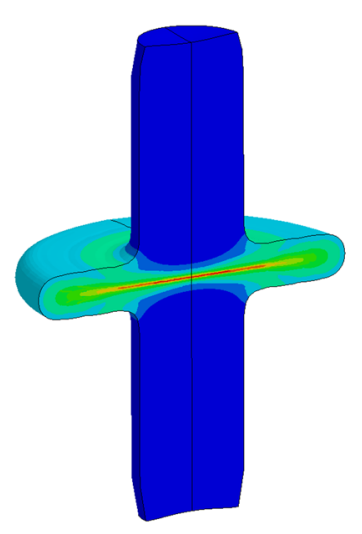

BCJ Model

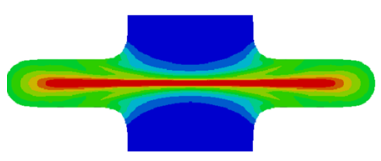

BCJ Model

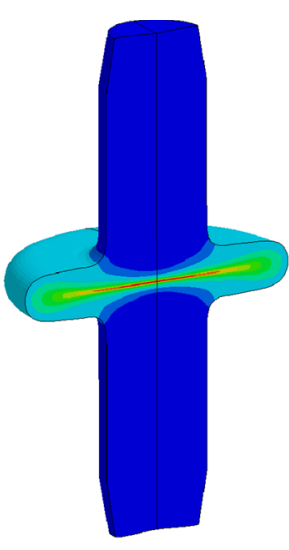

EMMI Model

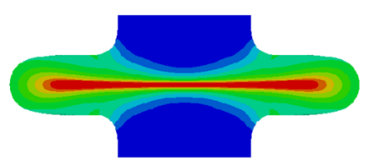

EMMI Model

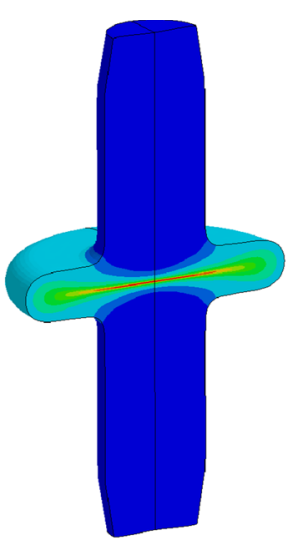

Fringe Levels

5.000 e+00

$4.500 e+00$

$4.000 e+00$

$3.500 e+00$

$3.000 e+00$

$2.500 e+00$

2.000 e+00

$1.500 e+00$

$1.000 \mathrm{e}+00$

5.000e-01

$0.000 \mathrm{e}+00$

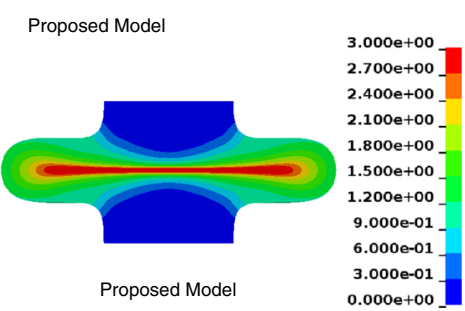


different initial temperatures with LS-DYNA on to the shaft, whereby the initial temperature for the $\mathrm{BCJ}$ model is applied in the material input card. Hence, the final temperature field from inductive heating is mapped onto the shaft as its initial temperature field prior to the forging process. For the EMMI and the proposed model, the calculated temperature field at the end of the heating step is mapped onto the shaft geometry at the beginning of the forging step (see Fig. 13, left). Due to the temperature initialisation in the material input card, the initial temperature belongs to the complete part subjected to the BCJ model. This approach requires a different part option for each initial temperature field. Due to the highly inhomogeneous temperature field, it is tedious to take the prior calculated temperature field into account for the analysis with the $\mathrm{BCJ}$ model. Instead, an approximation is applied with a piecewise averaged temperature field for a short section of the shaft (see Fig. 13, right).

Due to large temperature differences within the highly inhomogeneous temperature field, the locally different thermal expansion causes stresses in the shaft (see [16]) exceeding even the yield stress and, thus, provoking plastic deformations already during heating (see [16]). For simplicity and due to small extents, the residual stresses and the plastic deformations of the heating process are neglected at the beginning of the forging simulation.

\section{Simultaneous hot/cold forging}

The forging process emerges from a displacement controlled downward motion of the upper die. The initial free surface forging of the heated area becomes a die controlled process after contact occurs between the bulged area of the shaft and the dies. For the FE analysis, a thermal contact model is applied between the shaft and the dies allowing heat transfer from the workpiece to the dies. After reaching the final closing position of the upper die, the displacement control is switched into a force controlled simulation with a maximum load of up to $1000 \mathrm{kN}$ during the complete cooling step of 28 seconds forced in the flange area afterwards.

The forging step takes 3.2 seconds, whereby large deformations occur in the middle of the shaft. Therefore, the mechanical time step size has to be significantly smaller than the one for the heating simulation in order to achieve a temporally sufficient discretisation. The implicit simulation of the forging step is very time consuming due to its small mechanical time step size. For this reason, the forging step is run with an explicit time integration scheme. Thereby, the mechanical time step size is kept constant with a value of $1.0 \cdot 10^{-5}$ seconds enabled by the mass scaling option in LSDYNA-see [16]. The thermal time step size is 0.1 seconds during the forging process.

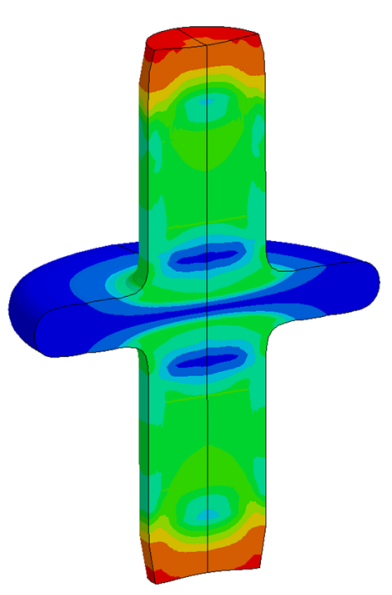

BCJ Model

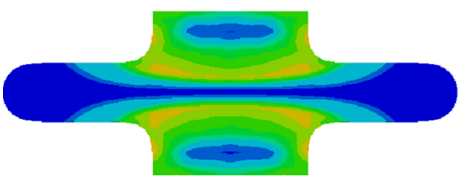

BCJ Mode

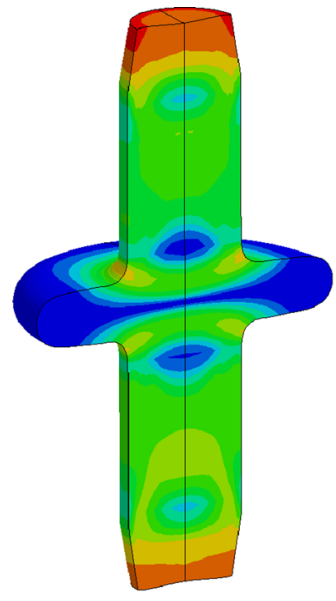

EMMI Model

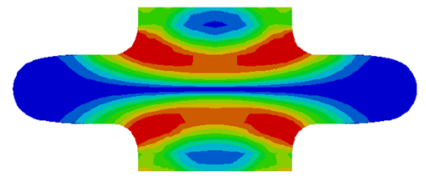

EMMI Model

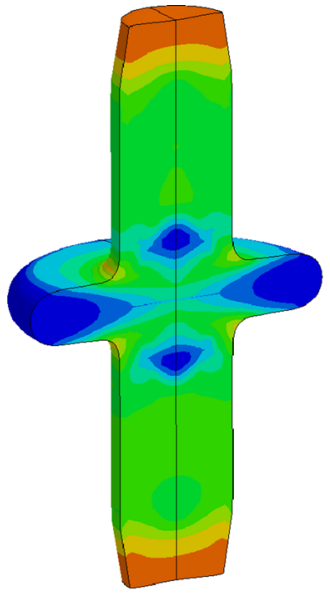

Proposed Model

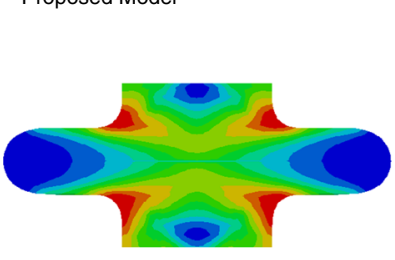

Proposed Model
Fringe Levels

$1.100 e+09$

$9.918 e+08$

$8.836 e+08$

$7.754 e+08$

$6.672 e+08$

$5.590 e+08$

$4.508 \mathrm{e}+08$

$3.426 e+08$

$2.344 e+08$

$1.262 \mathrm{e}+08$

$1.800 \mathrm{e}+07$

$.000 e+08$ $6.310 e+08$ $5.620 e+08$. $4.930 \mathrm{e}+08$. $4.240 e+08$ $3.550 e+08$ $2.860 e+08$ $2.170 e+08$ $1.480 e+08$ $7.900 e+07$ $1.000 e+07$

Fig. 15 VON MISES stress (in Pa) at the end of the hot/cold forging step with detailed view in the flange area 
The effective plastic strains are compared for the three material models in Fig. 14 at the end of the simultaneous hot/cold forging step. A detailed view of the effective plastic strain in the flange area is given in a reduced scale in Fig. 14, lower row. All of them predict large plastic deformations in the hot center of the shaft. Contrarily, the plastic deformations are very small due to cold forging at the ends of the shaft. With the EMMI and the proposed model, the plastic strains are concentrated in the core of the flange. Thereby, the maximum values of the plastic strains are very similar. The effective plastic strains are slightly lower for the BCJ model and show a larger extent in the flange area.

The effective stresses according to VON MISES are compared for the three material models at the end of the forging step in Fig. 15. A detailed view of the effective stresses according to VON MISES in the flange area is given in a reduced section in Fig. 15, lower row. With all of the three material models, the maximum stresses are located at the cold forged ends of the shaft, whereby the magnitudes are very similar. Due to the high temperature in the central part of the shaft, the stresses in the hot forged flange are approximately two orders of magnitude lower for all three material models. The stress distribution is different between the material models in the flange area. For the BCJ and EMMI model, the stress is nearly the same along the flange cross section. With the proposed model, the stress increases from the outer flange area to its core. The minimum stress values are very similar in the case of the BCJ and the proposed model, whereas a significant higher minimal value occurs in the EMMI model.

The temperature distributions at the end of the forging step are compared for the three material models in Fig. 16. A detailed view of the temperature distribution in the flange area is given for this section in Fig. 16, lower row. For the BCJ and the EMMI model, the temperatures of the material history are shown. Obviously, the thermal conduction in the shaft during the forging step does not work with the temperature saved in the material history of the BCJ and EMMI model. As a result, the very high temperatures in the middle section of the shaft resulting from heating (see [16] p. 285, Fig. 14) are localised in the core of the flange during the forging process. This localisation of high temperatures may lead to a softer mechanical behaviour under deformation. In accordance with the localised high temperatures, the stresses with the BCJ and EMMI model are very low in this area. The temperature from the thermal solution with the proposed model, is used and, therefore, the thermal conductivity leads to the cooling of the inner flange area during the forging step. Comparing the stresses and temperatures along the flange cross section, the stresses increase with decreasing temperature.

Comparing the initial temperatures in Fig. 13 with the result at the end of the forging step, the values of the BCJ and EMMI model have increased due to the conversion of plastic work into heat. As a result of the apparent absence of a fully thermo-mechanical coupling, no heat transfer of

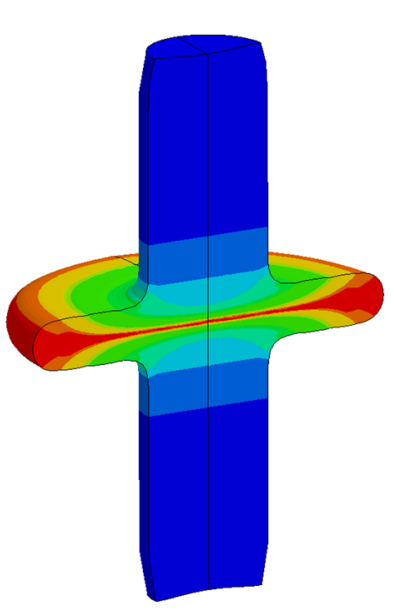

BCJ Model

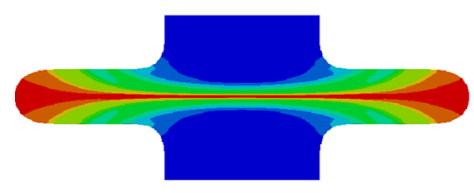

BCJ Model

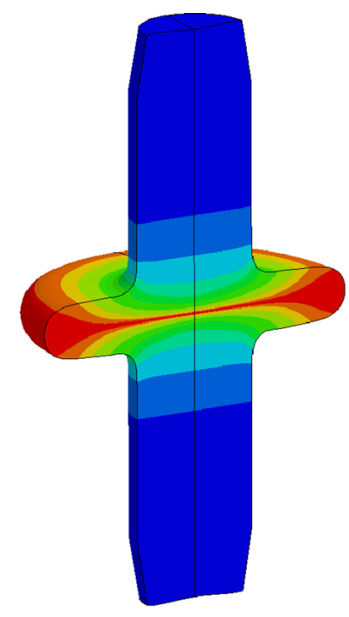

EMMI Model

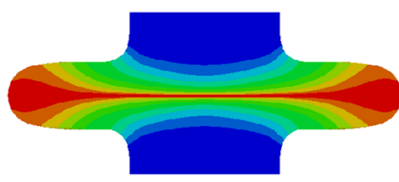

EMMI Model

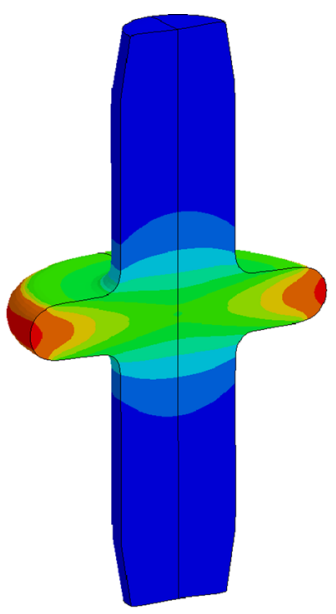

Proposed Model

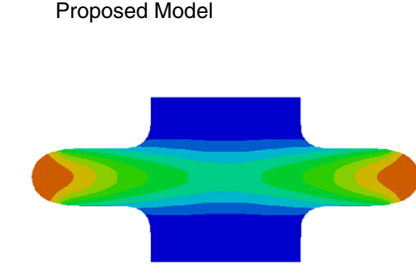

Proposed Model
Fringe Levels

$1.490 e+03$

$1.371 \mathrm{e}+03$

$1.252 e+03$

$1.133 e+03$.

$1.014 \mathrm{e}+03$

$8.950 e+02$

$7.760 e+02$

$6.570 e+02$

$5.380 e+02$

4.190e+02

3.000e+02 ]

Fig. 16 Temperature (in $\mathrm{K}$ ) at the end of the hot/cold forging step with detailed view in the flange area 


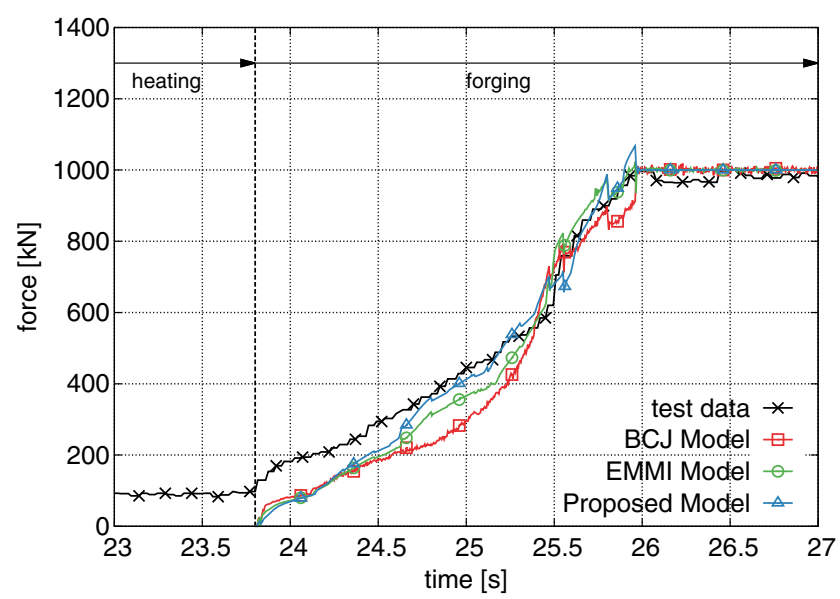

Fig. 17 Diagram of the calculated forging force with respect to time and the test data

the hot flange area to the dies is possible. For the proposed model, the contact between the hot flange and the dies leads to a small decrease of the maximum temperature. In spite of the small differences comparing the temperature distribution in the shaft, the simultaneous hot/cold forging analysis of the shaft can be used to validate the material models.

For the validation of the three constitutive models, the predicted forging force is compared to the test data 2 during the simultaneous hot/cold forging (see Fig. 17). The predicted force increase is very similar from the starting point at 23.8 seconds to approximately 24.5 seconds with all of the three material models. However, the test data is underestimated significantly with all of the three material models in this temporal range. The simulation results with the different material models vary widely between approximately 24.5 seconds and approximately 25.3 seconds. As a consequence of the poor prediction accuracy of the BCJ model (see Section "Evaluation and critical review of material models by means of stress-strain curves"), the test data cannot be captured precisely in this temporal range. Hence, the course of the force is underestimated significantly due to a too soft mechanical behaviour under deformation for low temperatures (see Fig. 9). For the EMMI model, the accordance with the test data is significantly better. The best agreement with the test data is achieved by the proposed model. After reaching the time point at approximately 25.3 seconds, the simulation results of all three material models differ slightly and are in good agreement with the experimental data.

The final geometric measurements from the three material models investigated are compared to the experimental

\footnotetext{
${ }^{2}$ The test data is kindly provided by Prof. Dr.-Ing. K. Steinhoff, Institute of Production Technology and Logistics, Chair of Metal Forming Technology, University of Kassel, Kurt-Wolters-Str. 3, 34125 Kassel (Germany)
}

values 2 in Fig. 18. The geometric measurements from the simulation and the experimental values as well as the relative deviation are depicted in Fig. 19 for a graphical interpretation. The shaft length $l$, the length of the conical shaft ends $k_{1}$ and $k_{2}$ as well as the flange diameter $d$ and the flange thickness $h$ is considered. The simulation with the $\mathrm{BCJ}$ model underestimates the final shaft length and the flange thickness. In addition, the flange diameter is overestimated significantly (see also Fig. 16). Furthermore, the length of the conical shaft ends is also highly underestimated. The shaft length, the flange diameter, and the flange thickness is predicted very well with the EMMI and the proposed model. The experimental values of the length of the conical shaft ends are unequal, whereas the simulation leads to nearly equal values. Thus, only the simulation result for the length of the lower shaft end $k_{2}$ is in good agreement with the experimental values. The deviation of the upper length of the conical end $k_{1}$ is approximately $20 \%$ for the EMMI and the proposed model.

Summarising the results of the validation example, the BCJ model is not suitable for the analysis of simultaneous hot/cold forging processes. The predicted mechanical response under deformation is too soft for the lower temperatures and leads to a significant deviation in the time course of the forging force as well as for the final geometric dimensions. For the EMMI and the proposed model, the final workpiece measurements are predicted very well, except for the upper length of the conical shaft end. The course of the forging force is predicted very well with both material models, however, the simulation with the proposed model leads to results closest to the experimental data.

\section{Summary and critical review}

Three different empirically deduced thermo-viscoplastic models are investigated for the purpose of a critical review and assessment for the FE analysis of a simultaneous hot/cold forging. Despite recently developed physics-based crystal plasticity models, empirical models are still widely employed for industrial applications. Physics-based models are based on a high number of model parameters to describe the mechanical behaviour of the material under deformation, leading to a high effort for the model parameter identification. Furthermore, unconventional test data from the microstructure is required. In contrast to this, the identification of empirical model parameters is based on standardised tests resulting in a straightforward identification procedure. A further disadvantage of crystal plasticity models is the high numerical effort for the simulation of large components due to the required homogenisation process. For this reasons, it is worth 
Fig. 18 Comparison of the final geometric measurements from the simulation with the three material models with the experimental values

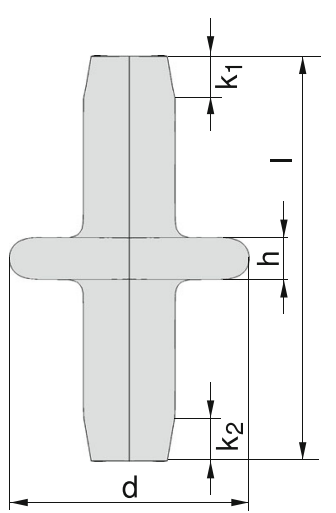

\begin{tabular}{llllll}
\hline & $k_{1}[\mathrm{~mm}]$ & $k_{2}[\mathrm{~mm}]$ & $h[\mathrm{~mm}]$ & $d[\mathrm{~mm}]$ & $l[\mathrm{~mm}]$ \\
\hline Experiment & 12.0 & 14.0 & 13.6 & 76.8 & 130.6 \\
BCJ Model & 9.0 & 9.0 & 11.6 & 88.34 & 121.8 \\
deviation in \% & -25.0 & -35.7 & -14.7 & 15.0 & -6.7 \\
EMMI Model & 14.4 & 14.3 & 13.5 & 79.0 & 133.3 \\
deviation in \% & 20.0 & 2.1 & -0.7 & 2.9 & 2.1 \\
Proposed Model & 14.3 & 14.3 & 13.5 & 78.0 & 133.7 \\
deviation in \% & 19.2 & 2.1 & -0.7 & 1.6 & 2.4 \\
\hline
\end{tabular}

to consider and further develop conventional model approaches. Here, a recently proposed user defined material model is applied besides the established BCJ and the EMMI model. The different temperature dependent functions for the initial yield stress, the isotropic hardening and the strain rate sensitivity are discussed briefly for the models. The model parameters are identified by fitting the simulation results to test data. Therefore, a number of flow curves are depicted in numerous diagrams for the verification. Considering a wide range of application, four different sets of test data are used, namely the case hardening steel $16 \mathrm{MnCr} 5$, the low carbon steel $\mathrm{C} 15$, the low alloy steel $50 \mathrm{CrV} 4 / 51 \mathrm{CrV} 4$ and the aluminium alloy $\mathrm{AlMgSi} 1$, for the model evaluation by means of a comparison of the numerical result and the measurement based on the mean squared error. In addition, the material models are validated by means of the analysis of a simultaneous hot/cold forging process of a shaft made of $51 \mathrm{CrV} 4$ steel. As a result of the model evaluation, the BCJ model is not suitable to predict the test data in the entire temperature range of simultaneous hot cold forging. Consequently, the final geometric measurements of the hot/cold forged shaft as well as the forging force differ significantly from the test data. The assessment of the simulation results with both the EMMI and the proposed model leads to a satisfactory agreement in the entire temperature range. Hence, both material models are basically suitable for the analysis of simultaneous hot/cold forging processes. However, the numerical results with the proposed model have the smallest deviations from the test data considered. The conducted model evaluation could be enhanced by crystal plasticity models for future investigations.

Acknowledgements The authors thankfully acknowledge the financial support of the German Research Foundation (DFG) through grant no. Ma1186/5-2.

Funding Information Open Access funding provided by Projekt DEAL.

\section{Compliance with Ethical Standards}

Conflict of interests The authors declare that they have no conflict of interest.

Open Access This article is licensed under a Creative Commons Attribution 4.0 International License, which permits use, sharing, adaptation, distribution and reproduction in any medium or format, as long as you give appropriate credit to the original author(s) and the source, provide a link to the Creative Commons licence, and indicate if changes were made. The images or other third party material in this article are included in the article's Creative Commons licence, unless indicated otherwise in a credit line to the material. If material is not included in the article's Creative Commons licence and your intended use is not permitted by statutory regulation or exceeds the permitted use, you will need to obtain permission directly from the copyright holder. To view a copy of this licence, visit http:// creativecommonshorg/licenses/by/4.0/.
Fig. 19 Bar diagrams of the geometric measurements from the simulation with the three material models and the experimental values (left) as well as relative deviation of the predicted values to the experiment in \% (right)
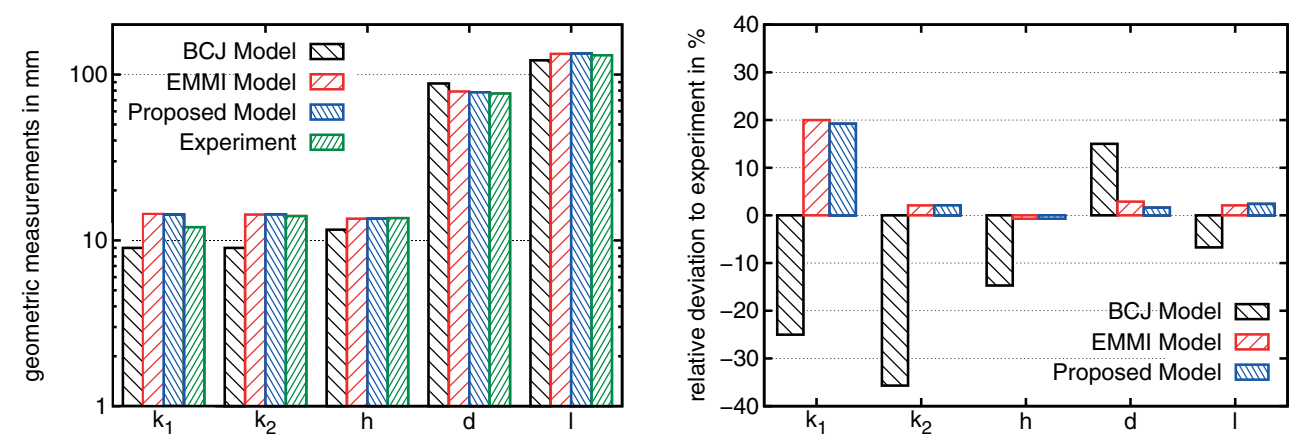


\section{References}

1. Bammann DJ (1990) Modeling temperature and strain rate dependent large deformations of metals. Appl Mech Rev 43(5S):312-319

2. Bammann DJ, Chiesa ML, Johnson GC (1996) Modeling large deformation and failure in manufacturing processes. In: Tatsumi T, Watanabe E, Kambe T (Eds.): Proceedings of the XIX th International Congress of Theoretical and Applied Mechanics, pp. 359376, August 25-31, Kyoto, Japan

3. Bever MB, Holt DL, Titchener AL (1973) The stored energy of cold work. Prog Mater Sci 17:5-177

4. Bröcker C, Matzenmiller A (2013a) thermoviscoplastic model with damage for simultaneous hot/cold forging analysis. In: Onate E, Owen DRJ, Peric D, Suarez B (Eds.): Proceedings of 12th International Conference on Computational Plasticity Fundamentals and Applications (COMPLAS XII), pp. 778789, September 03-05, 2013, Barcelona, Spain

5. Bröcker C, Matzenmiller A (2013b) An enhanced concept of rheological models to represent nonlinear thermoviscoplasticity and its energy storage behavior. Continuum Mechanics and Thermodynamics 25:749-778

6. Bröcker C, Matzenmiller A (2014) On the generalization of uniaxial thermoviscoplasticity with damage to finite deformations based on enhanced rheological models. Technische Mechanik 34:142-165

7. Bröcker C, Matzenmiller A (2015) An enhanced concept of rheological models to represent nonlinear thermoviscoplasticity and its energy storage behavior, part 2: spatial generalization for small strains. Continuum Mechanics and Thermodynamics 27:325-347

8. Bröcker C, Steinhoff K, Matzenmiller A (2008) Process simulation of stub shaft forging with local heating and cooling an analysis with EFG. Computer Methods in Materials Science 8:144-153. Publishing House AKAPIT, Krakow, Poland, 2008

9. Chrysochoos A, Maisonneuve O, Martin G, Caumon H, Chezeaux JC (1989) Plastic and dissipated work and stored energy. Nucl Eng Des 114(3):323-333

10. Doege E, Behrens BA (2010) Handbuch Umformtechnik Grundlagen. Technologien, Maschinen, Springer Verlag

11. Hagen M (1990) Werkstoffmodelle zur thermomechanischen Behandlung des Stahls 50CrV4. PhD Thesis Faculty of Mining, Metallurgy, and Geosciences, RWTH Aachen University

12. Livermore Software Technology Corporation (LSTC) (2015) LSDYNA Keyword user's manual, volume II, Material Models. Livermore, California, USA, LS-DYNA R8.0, 03/18/15 (r:6307)
13. Maikranz-Valentin M, Saba N, Weidig U, Göken J, Steinhoff $\mathrm{K}$ (2008) Investigation on functionally graded 51crv4 and its damping behaviour. In: 9th International Conference on Technology of Plasticity (ICTP), pp. 2283-2288, September 0711, 2008, Gyeongju, Korea

14. Marin EB, Bammann DJ, Regueiro RA, Johnson GC (2006) On the formulation, parameter identification and numerical integration of the EMMI model : plasticity and isotropic damage. SANDIA REPORT, Sandia National Laboratories, Albuquerque, New Mexico 87185 and Livermore, California 94550. https://doi.org/10.2172/883488

15. Matzenmiller A, Bröcker C (2009) Modeling and Simulation of Coupled Thermoplastic and Thermoviscous Structuring and Forming Processes. In: Maier HJ, Steinhoff K, Biermann D (Eds.): Functionally Graded Materials in Industrial Mass Production, pp. 235-250,Verlag Wissenschaftliche Skripten, Auerbach, Germany

16. Matzenmiller A, Bröcker C (2012) Thermo-mechanically coupled $\mathrm{FE}$ analysis and sensitivity study of simultaneous hot/cold forging process with local inductive heating and cooling. Int J Mater Form 5:275-300

17. Matzenmiller A, Bröcker C, Gerlach S (2009) FE-Analysis of Simultaneous Hot/Cold Forging. Steel Res Int 80(2):130-136

18. Saarstahl AG (2017) Material specification sheet saarstahl 51crv4 (50crv4). Accessed 22 May 2017. www.saarstahl.com/sag/ downloads/download/11561

19. Simo JC, Miehe C (1992) Associative coupled thermoplasticity at finite strains: Formulation, numerical analysis and implementation. Comput Methods Appl Mech Eng 98(1):41-104

20. Stander N, Roux W, Basudhar A, Eggleston T, Goel T, Craig K (2014) LS-OPT User's Manual - A Design optimization probabilistic analysis tool for the engineering analysist.Livermore Software Technology Corporation (LSTC), Livermore Software Technology Corporation (LSTC), Livermore, California, USA, Version 5.1

21. Steinhoff K, Weidig U, Scholtes B, Zinn W (2005) Innovative flexible metal forming processes based on hybrid thermomechanical interaction. Steel Res Int 76(2-3):154-159

22. Taylor GI, Quinney H (1934) The latent energy remaining in a metal after cold working. Proceedings of the Royal Society of London a: Mathematical. Phys Eng Sci 143:307-326

23. Weidig U, Hübner K, Steinhoff K (2008) Bulk steel products with functionally graded properties produced by differential thermomechanical processing. Steel Res Int 79(1):59-65

Publisher's note Springer Nature remains neutral with regard to jurisdictional claims in published maps and institutional affiliations. 